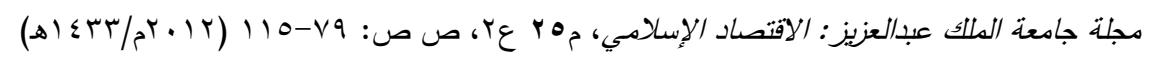
DOI: 10.4197 / Islec. 25-2.3

\title{
المفهوم التسويقي الحديث وجهة نظر إسلامية
}

\author{
طارق بلحاج

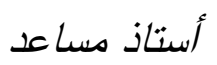 \\ معرة العلوم التجارية والتسبيير، المركز الجامعي - ميلة - الجزائر \\ t.belhadj@centre-univ-mila.dz
}

الستخلص. لقد استعرضنا في هذه الورقة أهم المراحل التي مر بها

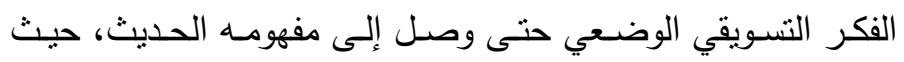

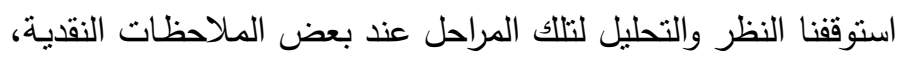

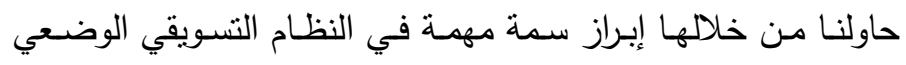

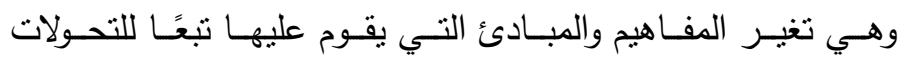

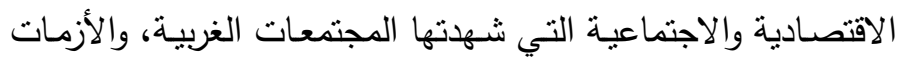

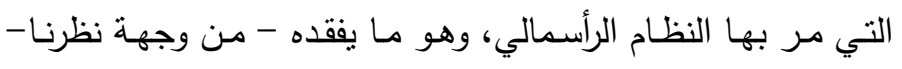

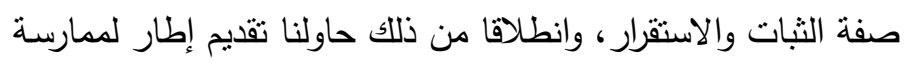

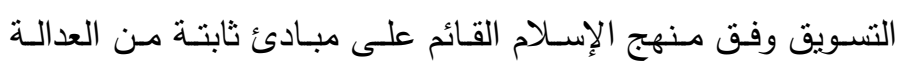

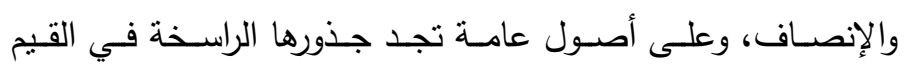

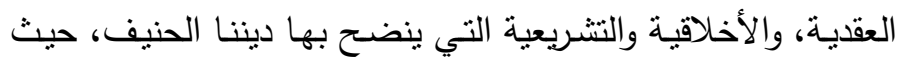
اقترحنا تعريفا لمفهوم التسويق الإسلامي. 


\section{مقدمة}

إن ظهور إطار للفكر التسويقي كان في بداية القرن العشرين من الأدبيات التي أسسـها الاقتصـاد الكلاسيكي، والتي وجدت الدعم في الرأسمالية الصناعية القائمـة على السوق الحرة لآدم سميث، ومبدأ "دعه يعمل دعه يمر" و "اليد الخفية" كآلية والية للتحكم والرقابة، إضافة إلى النظرة المادية التاريخية التي طبعت الفكر الماركسي، وكذلك مفهوم ماكس ويبر عن الرجل الاقتصادي العقلاني، ومبدأ داروين في البقاء للأصلح، كل هذه المعاني خلقت العلمانية، والقيم المحايدة، التي أدت إلى إنتاج مجتمع مغرق في المادية، يسعى لخدمة المصسالح الذاتية بتعظيم الثروات وإثباع الرغبات (Mahboub and Shariful, 2011, 71-72)، غير أن هذا الفكر التسويقي شـهد تغيـرًا وتطـورًا بشـكل مسـتمر وفق مراحل متعددة، حيـث اختلفت الفلسـفات والمفاهيم الموجهة لـه في كل مرحلـة نتيجـة التغير في البيئة الداخليـة والخارجيـة لمنظمـات الأعمـال لتصـل إلى المفهوم التسـويقي الحديث، وخـلال الأزمـة الماليـة

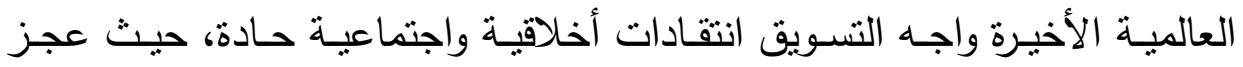

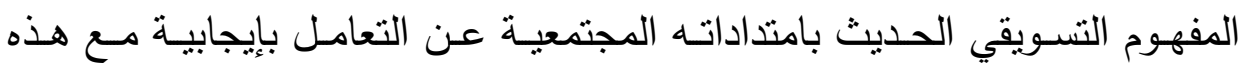

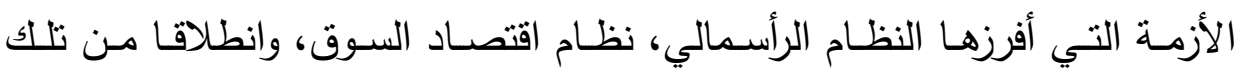

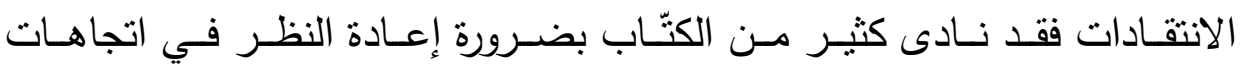

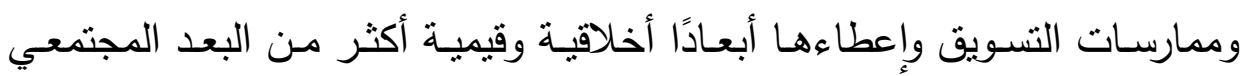

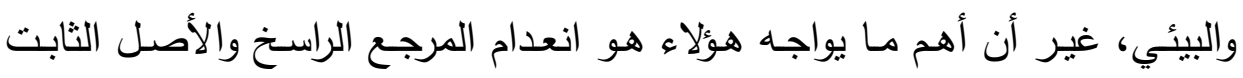

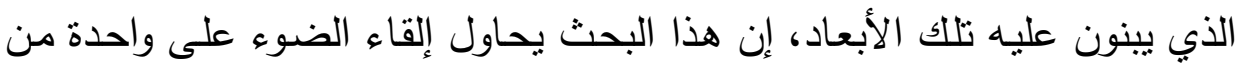
أهم المشكلات التي تواجه صنّاع القرار في المؤسسات الاقتصادية، وهي مشكلة التهنة أخلقة التسويق وحسن استخلال تقنياته المتعددة في تحقيق الصسالح العام، وفي ظل

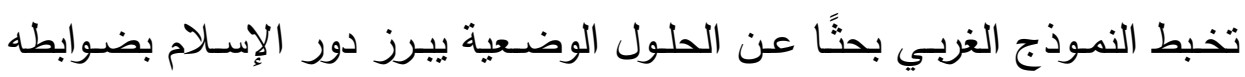

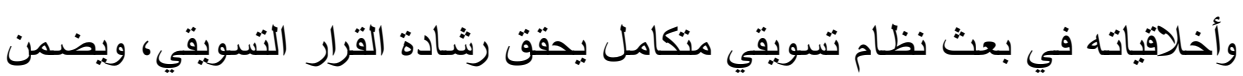


عدالة العلاقة بين المنتج والمستهلك في ظل احترام مصالح المجتمع، من هنا تأتي أهية دراسة المنظور الإسلامي للتسويق.

\section{المبحث الأول: تطور الفلسفة والمفاهيم التسويقية}

تطرق هذا المبحث إلى أهم المراحل التي تطور خلالها الفكر التسويقي حتى

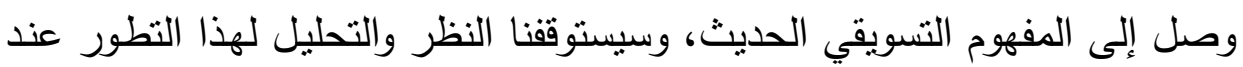
بعض الملاحظات النقدية، حيث سنسعى إلى إبراز سمة مهمة في النظام التسويقي

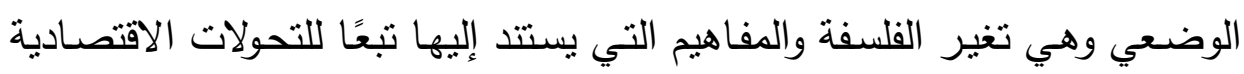

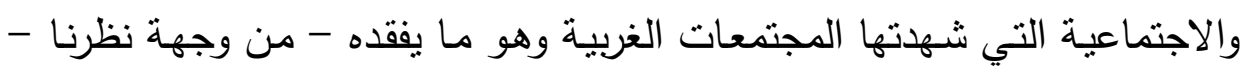

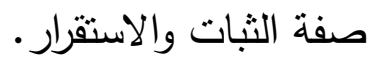

\section{المطلب الأول: المفهوم التسويقي الحديث}

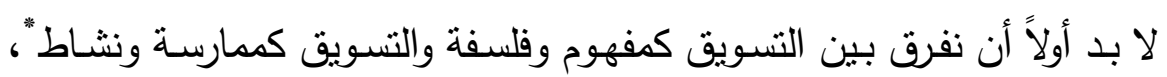

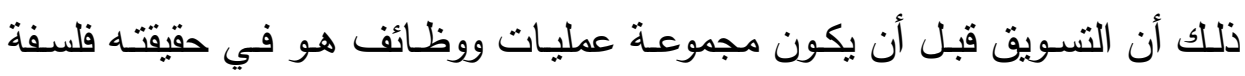

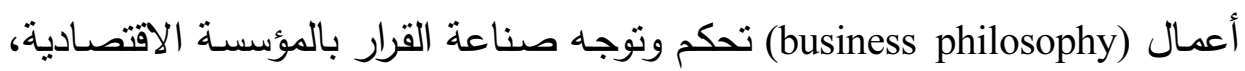

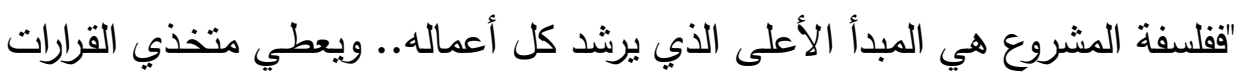

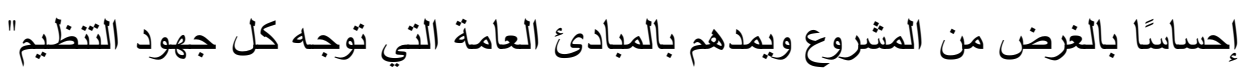

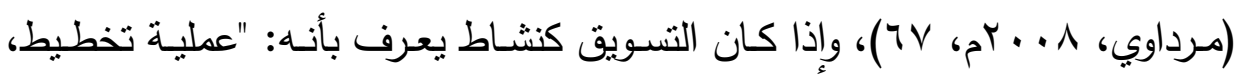

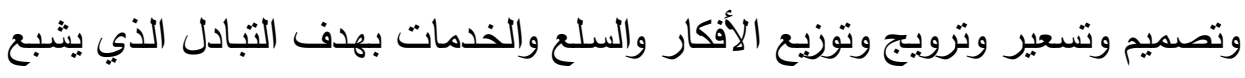

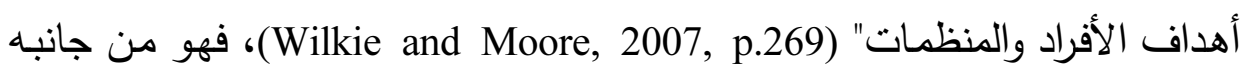
الفلسفي طريقة تفكير ومن الطبيعي أن طريقة التفكير تحكم وتحدد ماهية الأنشطة

* الباحث يثكر المحكم الكريم الذي نبهه إلى ضرورة التفريق بين التسويق كمفهوم والتسويق كممارسة،

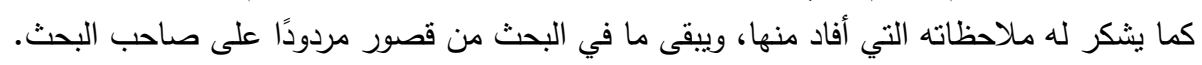


(الثـواني، · . . . م، YV)، والجدير بالذكر أن هذه الفلسفة أو طريقة التفكير لـ تكن واحدة على مـر الزمن، وإنمـا كان هنالك انتقال مـن فلسفة لأخرى كنتيجـة للتغيرات التي عرفتها منظمات الأعمال في المجتمعات المتقدمة.

لقد قدم كيـ (Keith, 1960) أول دراسـة تحليليـة لتطور التسـويق كفلسـفة أعمال من خلال مؤسسته التي كان بشتخل بها حيث ميز بين أربع مراحل، في حين يرى بعضهم (Pride and Ferrell, 2000) أن هذه المراحل تتحدد في ثيلاث كما يلي: مرحلة التوجه الإنتاجي، والتوجه البيعي، ثم مرحلة التوجه التسويقي. غير أن الذي استقرت عليه أدبيـات التسـويق هو التقسيم الذي قدمـه كوتلر خلال فترة السبعينيات حيث أضاف مرحلتين لصيقتين بكل من المرحلة الأولى والثالثة هما: مرحلة التوجهه بالمنتوج وهي امتداد لمرحلة التوجه الإنتاجي، ومرحلة التوجه المجتمعي وهي امتداد لمرحلة التوجه التسويقي (Kotler, 2002). أولا: المفهوم الإنتاجي: لقد ساد هذا المفهوم منذ منتصف القرن التاسع عشر حتى الربع الأول من القرن العثرين، حيث كانت المنظمات التي مرت بمرحلة الثورة الصـناعية تعمل في ظل منافسـة محدودة وسـوق تهيمن عليـه قوة المنتجين، أيـن تطغى مشكلة الإنتاج على تفكير القائمين بالنشاط في تلك المنظمات، لقد كانت إمكانات الإنتاج قاصرة عن إثباع حاجات السوق، وفي ظل الاعتقاد السائد بصحة الفرض الاقتصادي المعروف آنذالك بقانون ساي للمنافذ الذي ينص على أن العرض يخلق الطلب الخاص به، كان هدف المؤسسات هو تحسين كفاءة الإنتاج (من أجل

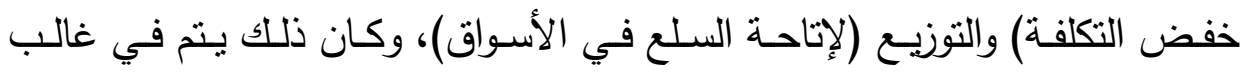
الأحيان عن طريق الإنتاج الكبير (mass production) وتوحيد مواصفات المنتوج مــع إهــال مطلـق لخيـارات المسـتهلكين فـي هـذا المجـال (standard items) (Lancaster and Massingham, 2011, p.04) حيث يفترض المفهوم الإنتاجي أن 
المستهلك ليس لله بد من شراء منتجات المؤسسة ولهذا لم يكن مستغربًا ألا يبذل المنتجون إلا جهدًا يسيرًا لا يعدو تدريب رجال البيع لتصريف منتجاتهم.

ونتيجة لذلك فقد كانت إدارة الإنتاج هي مركز نشاط الأعمال بالمنظمات، أما الوظائف الأخرى فهي أقل أهمية كإدارة الموظفين، والمالية، والبيع. هذه الأخيرة

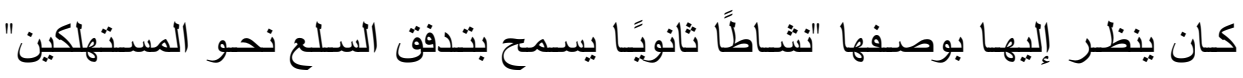
.(Demeure, 2008, p.03)

ثانيا: مفهوم المنتوج: عرفت هذه المرحلة ظهور المنافسة بين المنتجين إذ لم تعد الأسعار المغربـة المتأنيـة من تخفيض تكاليف الإنتاج قادرة لوحدها على جذب

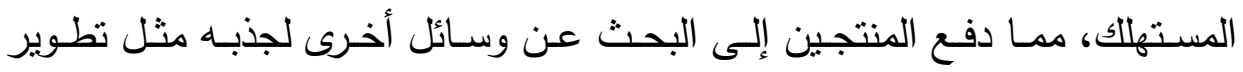
مواصفات السلع، وعلى هذا الأساس قام المفهوم المتعلق بالمنتوج، والذي يفترض أن المستهلكين يختارون المنتجات والخدمات ذات الجودة العالية والأداء الجيد، ما يعني أن المؤسسة عليها في ضوء ذللك أن تتبنى استراتيجية لتطوير منتجات ذات جودة متميزة، وتحسينها من حين لآخر (Vandarcammen, 2002, p.26)، وبعبارة أخرى فإن تفكير الإدارة في المنظمات التي تتبنى هذا المفهوم يتمنل في أنه إذا قام الفنيون والمهندسون بتصميم المنتوج على نحو مرضٍ فنيّا فإن مهمة رجال البيع تكون سهلة أو بالأحرى ثانوية على اعتبار أن "المنتوج الجيد يبيع نفسه" (Payne, 1988, p.03). ومسع تركيزهـا على الجـودة أصـبحت الهندسـة هـي النشـاط المهـيمن في سي المنظمات (أمريكا وأوروبا) حيث إن الموقف السـائد آنذالك في أوسـاط العديد من الشركات هو تصميم وهندسة أفضل المنتجات، ذلك أن الاعتقاد بعقلانية المستهلك تفترض أنه سيشتري المنتجات ذات الجودة الأعلى، غير "أن التركيز على جودة المنتوج قد يقود إلى الهوس التكنولوجي حيث يعتقد المدراء أن التفوق التقني هو مفتاح النجاح في نشاط الأعمال" (Kotler, et al., 1999, p.18). 
فالتوجه بهذا المفهوم قد يقود إلى بعض النجاح ولكنه في نهاية الأمر سيؤدي بالمؤسسة إلى الوقوع فيما سماه (Levitt Theodore) "قصر النظر التسويقي" حيث التركيز على خصائص المنتوج بدل احتياجات المستهلكين، فقد بيّن أن الثركات التي تعرف مجال نشاطها تعريفًا ضيقا من منظور منتجاتها أو منظور التكنولوجيا التي تتتج تلك المنتجات ستواجه خطر الزوال حتى ولو كانت حاجات المستهلك التي تستهدفها تتميز بنمو مطرد، وسيكون ذلك النمو في صسالح الثركات التي تعرف نشاطها وفق حاجات المستهلك،" إن تلك المنظمات التي تتبنى هذا المفهوم (المنتوج) إنما ترى نفسها من خلال المرآة بدل أن تطل من النافذة على الخارج أين يوجد المستهلكون" (Levitt, 1975, p.14).

ثالثـا: المفهـوم البيعي: لقد قـادت تقنيات التصـيع المتقدمة وأسـاليب الإدارة العلميـة خـلال هذه المرحلـة إلى تحسـين القدرات الإنتاجيـة للمنظمـات التي كانـت تسعى إلى تحقيق وفرات الحجم (Economies of scale) عن طريق أنظمة الإنتاج الكبير ، هذا الإنتاج الكبير الذي أدى إلى اختلال التوازن بين الإنتاج ممثنل في العرض وبين الاستهلاك ممثلا في الطلب، حيث عجزت أنظمة التوزيع عن التعامل مع فائض العرض وتصريفه في الأسواق، وهو ما كان نذيرًا لأزمـة الكساد العالمي عام 9ب9 (م، وحيث إنهارت فرضية سـاي (العرض يخلق الطلب عليه) "فقد بـدأ

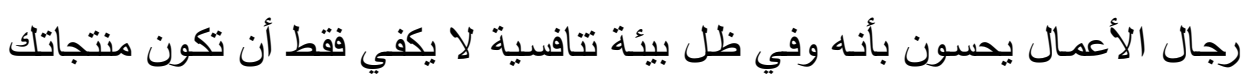
عاليـة الجودة والأداء ولكن أيضـا يجب البحث في كيفيـة تصريفها، لقد تم الاقتتاع بأن السلع لا تبيع نفسها مهها كانت جودتها على الأقل دون بعض الجهود البيعية (التروبجية)" (Geoff and Paul, 2005, pp:10-11)

وحسب (Thomas Powers) فقد ساد الاعتقاد في تلك الفترة بأن هناك تقصيرًا

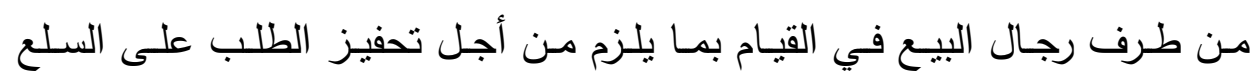


والخـمات، وتم تعربـف أزمسة الكسـاد في المؤسسـات على أنهـا مشـكلة "بيـع" أو "توزيع" في المقام الأول وعلى رجل البيع التغلب عليها في إطار ما صـار بعرف "بالمنافسة الجديدة"، فهع هذا المفهوم كان هنالك إيمان راستخ بأن تقنيات وأسـاليب

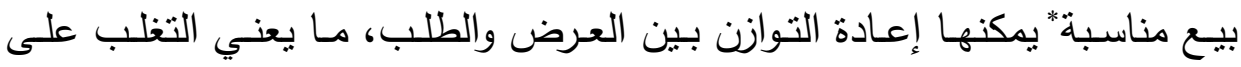
ظاهرة الكساد (Powers, 1991, p.246).

وحتى وإن شـهدت هـذه المرحلـة نمـو المنافسـة بـين المنتجين وتكثقهـا حـول قنوات التوزبـع، لابـد أن نلاحظ أن هذه المنافسـة كانـت تتم انطلاقا من منتجـات صنعت ابتداء ثم يحاول بيعها ودفعها إلى السوق الاستهلاكي، فالمفهوم البيعي يمكن تعريفه بأنـه توجـه إداري يقوم على أن المسـتهلك سبثـتري المنتجـات ذاتها وبكميـة كافـة طالمـا أن الثـركة خصصست مـا يكفي مـن الجهود لحفز الاهنمـام والطلب لدى المستهلك، إذًا " فاللهف دائماً هو بيع ما تم صنعه بدلا من صناعة ما يريده السوق" (Kotler and Armstrong, 2008, p.10). رابعـا: المفهـوم التسـويقي: في مقالـه الثـهير "الثورة التسـويقية" استشـرف (Robert Keith, 1960) مؤسسة (Pillsbury) أين كان يشخل منصب نائب الرئيس فقال: "إن المستهلك هو * لقد استمر هذا المفهوم البيعي حتى ستينيات القرن العشرين، وحيث كان هناك القليل من تشريعات حماية المستهلك فقد سقط العديد من المستهلكين فريسة لتلك التقنيات دون إنصاف من جانب القانون، إن الكثير من تلك الممارسات غير الثريفة التي شكلت ما اصطلح عليه في أدبيات التسويق بأساليب البيع العنيف (Agressif selling) والتي كانت تمارس علنًا، أصبحت الآن من الجرائم التي تعاقب عليها القوانين الجنائية في مختلف الدول، لقد تحركت كثير من الحكومات خلال السبعينيات وقدمت قدرًا أكبر من التشريعات لحماية المستهلكين ولذلك فإنه كثثرا ما يقال إن تلك الحقبة من التوجه البيعي هي ما أعطى صورة سيئة عن التسويق في الذاكرة الجماعية للجمهور لا تزال قائمة إلى اليوم، فقد كان ينظر إلى أنه من التجاوز وصف التوجه الإنتاجي بأنه توجه غير أخلاقي، ذلك أنه أعطى للمستهلك فرصة

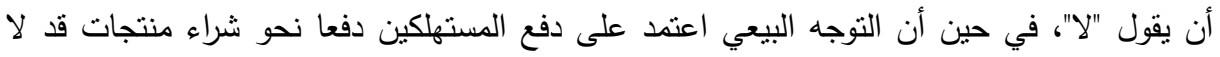

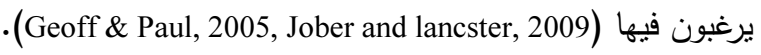


مركز الاهتمام وليس الثركة.. فالثركات تدور حول المستهلك وليس العكس.. إن اهتمامنا تحول من مشاكل الإنتاج إلى مشاكل التسويق، من المنتوج الذي يمكن أن نصنعه إلى ذلك الذي بربد المستهلك أن نصنعه، من الثركة إلى السوق.. فالثورة التسويقية بدأت للتو .. وسيصبح التسويق هو القوة المحفزة للمؤسسة بأسرها، قريبا سيأتي اليوم الذي يكون فيـه هدف جميـع نشـاطات الثـركة - التمويـل، والبيـع، والإنتاج.. - هو إثباع حاجـات المستهلك ورغباته، وحين يأتي ذلك اليوم تكون الثورة التسويقية قد اكتملت" (Keith, 1960, pp: 35-39).

وبالفعل أدت التغيـرات الاقتصـادية والاجتماعيـة التي أعقبـت نهايـة الحـرب العالميـة الثانيـة إلى تحـول جذري في فلسـفة إدارة أنشـطة الأعمـال، فــع بدايـة الخمسينيات كانت الدول الصناعية قد اجتازت مرحلة اقتصسادات الحرب ومن ثم بدأت معدلات الإنتاج تنزايد مع تعدد وتتوع في المنتجات تبعًا للتطور الحاصل في تقنيات وأسـاليب الإنتاج، لقد استطاعت أوروبـا بعد سـنوات أن تقدم إلى السـوق

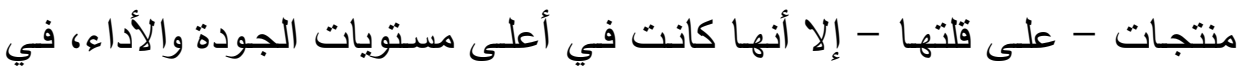
حين جعلت آسيا - ممثلة باليابان - تلك المنتجات أقل تكلفة من ذي قبل، أمـا المؤسسـات الأمريكيـة فقد بقيت معتمدة بشكل أساسي على مزايـا الإنتاج الكبير والتوزيـع الثـامل، ورغم أن تلك المؤسسـات كـان لها مـن الخبـرة مـا يفوق بكثير مثيلاتها الأوروبية واليابانية التي كانت لا تزال تفتقد إلى الكفاءة في الإنتاج، إلا أن الولايات المتحدة واجهت منافسة قوية للمرة الأولى منذ هيمنتها على نشاط الأعمال الدولي، وفي جيل من المسيرين لم يكن مستعدا لتلك المنافسة اتجهت الشركات الأمريكية بنهاية الستينيات إلى فقدان مزاياها التتافسية أمام تلك القوى الصاعدة في أوروبا وآسيا، إن وضعية الوسط التي كانت عليها لم تعد ذات جدوى، فلا منتجاتها كانت ذات جودة أعلى ولا هـي ذات أسـعار أرخص بمـا يكفي لإقناع المستهلك 
وتحقيق النجاح (Russell, 2010, p.21)، حيث وقعت الثركات الأمريكية تمامًا فيمـا عنـاه (Levitt) بقصـر النظـر التسـويقي، فمـع تركيزهـا على تقنيـات الإنتـاج وهندسـة المنتـوج فثـلت فـي مسـايرة التطـورات الحاصــلة فـي رغبـات وأذواق المستهلكين، وحيث تأكد لتلك الثركات أن الإنتاج الجيد للسلع والترويج لها عن طريق أساليب البيع المختلفة أصبحا غير كافيين لضمان النجاح في سوق تتافسي، فقد اسـتدعى الأمـر تغييرًا في فلسـفة الإدارة نحو تبنـي مـا بـات يعـرف بـالمفهوم التسويقي.

لقد صور (Wenderman) هذا التحول فقال: " أثناء الثورة الصناعية كثيرا ما كنـا نسـمع المنتـج يـردد، هـذا مـا أنتجـه، مـن يريـــ شـراءه ؟ ولكن وفـي عصـر المعلومات فإن المستهلك هو الذي يقول بصوت أعلى: هذا مـا أرغب فيه، هل يمكنك أن تصنعه لي؟ " (Kotler, 2003, p. XII).

إن المفهوم التسوبقي ليس تعربفا آخر للتسويق ولكنه أسلوب تفكير أو فلسفة إدارة، وعندما تعتتق المؤسسة هذه الفلسفة فإنها لا تؤثر على الأنشطة التسويقية فحسب ولكنها تؤثز على جميع أنشطة المؤسسة، أين تكون كافة القرارات الإدارية مرتبطـة بمـدى قدرتها ونجاحهـا في إثـباع المسـتهلك وتحقيـق رضـاه، فالعمليـة

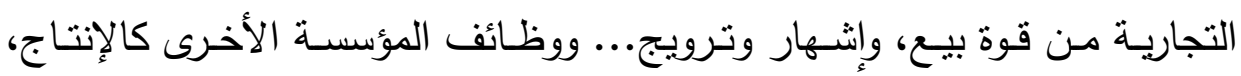
وإدارة الأفراد.. كل تلك العمليات وهذه الوظائف يجب أن تتبثق عن استراتيجية واحدة انطلافًا من رغبة المستهلك.

خامسـا: المفهوم المجتمعي للتسويق: إن المفهوم التسوبقي ما لبث أن لاقى جدلاً واسعًا على خلفية الانتقادات الاجتماعية والبيئية التي وجهت إليه والتي تطرقت لمواضيع مثنل: طغيان النزعة المادية على المؤسسات، والاستهلاك غير المنضبط للمنتجات والترفيه والموغل في الإسراف، ومظاهر الخداع والتلاعب التسويقي، وخلق 
رغبات لا معنى لها، المساهمة في ازدياد الهوة بين الفقير والغني، التلوث والفساد البيئي، استتفاد الموارد الطبيعية .. كل هذه كانت أسبابًا كافية لتوقد النقاش حول "دور التسويق في المجتمع" (Lazer, 1969)، وقد أدى ذلك النقاش إلى بروز حركات

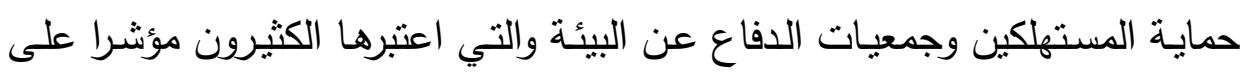

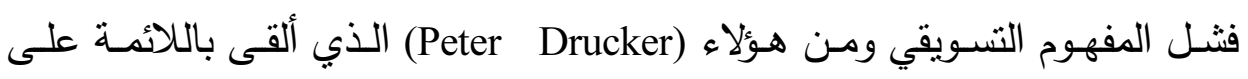
المسوقين الذين فثنوا في تطبيق المفهوم التسويقي لصالح المستهلك والمجتمع حيث يقول " إن ظهور حركات المستهلكين بعد مـا يقرب مسن عشرين عامًا على تبني خطـاب المفهوم التسـويقي هـو دليـل على فنــل تطبيـق هــا المفهوم، إن حركـة

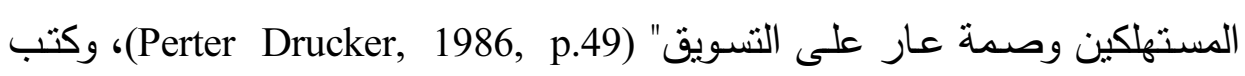
(Kotler, 2004) مقالا بعنـوان "الصـراع مـع الأخـلاق" أثـار فيـه إلى أن المفهوم التسويقي "اعط الزبون مـا يريد" أثنار قلق واهتمـام المفكرين والبـاحثين إزاء الزبـائن

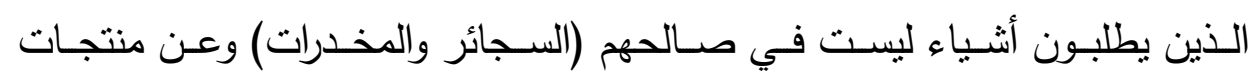
وخدمات تسيء إلى المجتمع وإلى الطبيعة مثل (المدافع والسيارات التي تتبعث منها ملوثات البيئة..)، بينمـا اعتبر (Gregory, 1990) أن المفهوم التسويقي ضـروري ولكنه لم يكن كافيًا لوفاء المؤسسة بالتزاماتها وخاصة في المجال البيئي. من أجل ذلك فقد ارتفعت الأصـوات وظهرت الكتابـات التي نـادى أصـابها بمطالب اجتماعية جديدة على النظام التسويقي، وفي مقدمتهم (Kotler) الذي قدم فلسفة التسـويق المجتمعي التي عرفها في كتابـات لاحقـة بأنها " التوجـه الإداري الذي يعتبر المهمـة الأساسية للمؤسسـة هـي تحديد احتياجـات ورغبـات الأسـواق

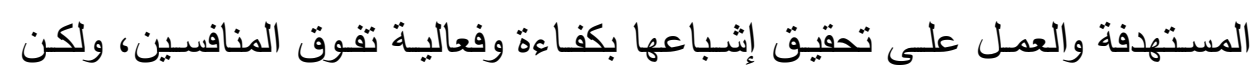
بطريقة تحافظ وتدعم التكامل بين حاجات المستهلك والمجتمع لتحقيق حياة أفضل للجميع" (Kotler, 2002, p.14). 
المطلب الثاني: الأزمات الاقتصادية وتطور القلسفة التسويقية لقد ادعى شانكر (Shankar) أن الفلسفة الحديثة للتوجه بالمستهلك (المفهوم

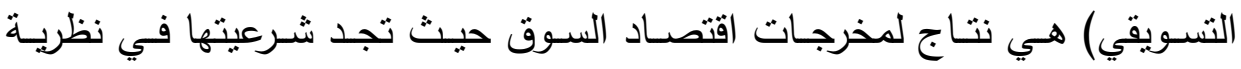

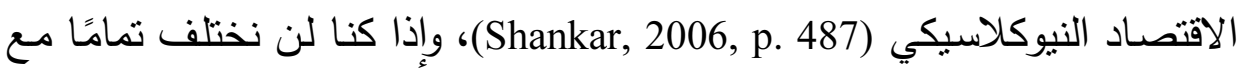

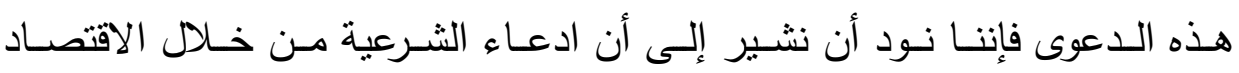

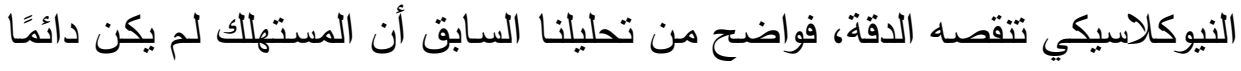

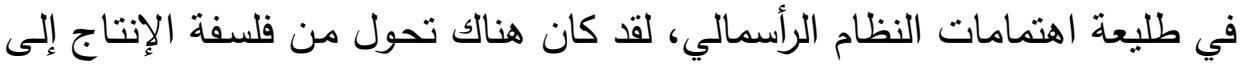

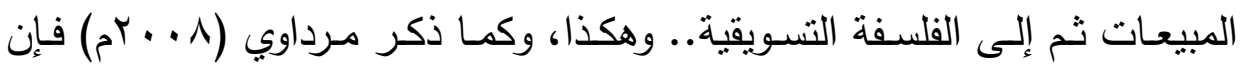
توجه مؤسسات الأعمال نحو تبني الفلسفة التسويقية لم يكن عفويًا أو تلقائيا وإنما

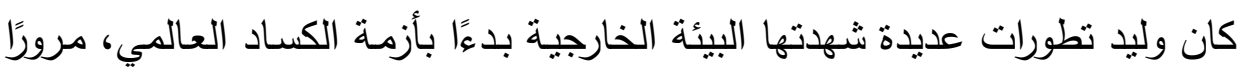

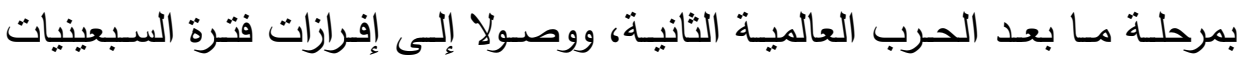

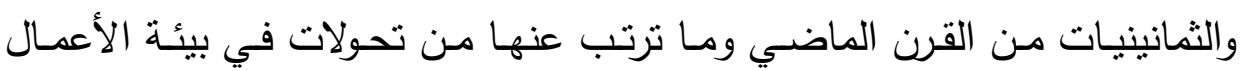
( $(v \leqslant)$

ولذلك سنناقش منتقدين هذا التغير المستمر في فلسفة التسويق، وسنبين أن النيا ذللك التغير هو سمة من سمات الفكر التسويقي الوضعي، وأنه كان دائًَا مرنبطًا بأزمات اقتصادية عميقة شهدها النظام الرأسمالي ولا يزال.

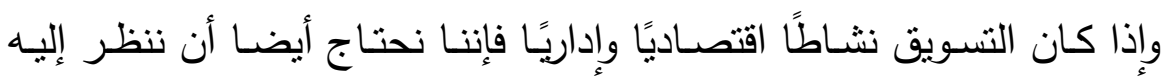

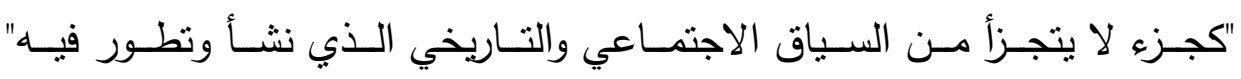

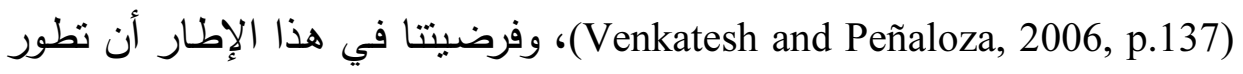

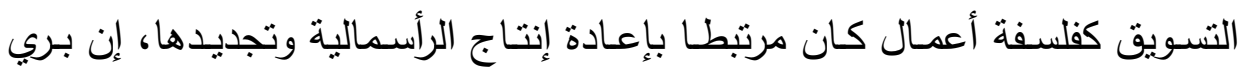

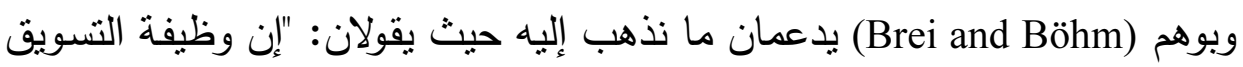

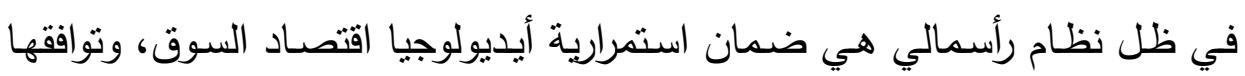

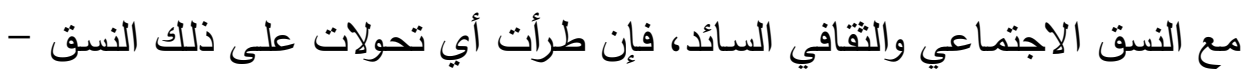


وخاصـة إن كانت تلك التحولات تهدد أسس الرأسمالية- فإن مهمة التسويق تبقى هـي إيجـاد طـرق جديـدة لبيـع المنتجـات والخـدمات بمـا يضــن اسـتمرار التـراكم الرأسمالي، وفي الوقت ذاته إيجاد طرق جديدة لإضفاء الثرعية على ذلك النظام" لئح .(Brei and Böhm, 2008, p. 12)

لقد كانت أزمـة الكساد العالمي حدًا فاصـلا في التوجها من المفهوم الإنتاجي

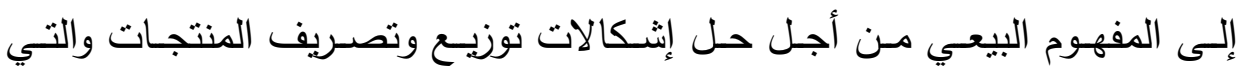
واجهتهـا مؤسسـات الأعمـال آنـذاك، هـذه الأخيـرة التـي طالمـا آمنـت بفرضـيات النموذج الكلاسيكي للاقتصاد الرأسمالي ومنها أن العرض يخلق الطلب الخاص بـه هؤس وأن النقود لا تكتسب إلا لغرض إنفاقها، وهي الفرضيات التي تهاوت أمام حقائق الأزمة الاقتصادية عام 9 و ام، إن التوجه نحو المفهوم البيعي في تلك الفترة لم يكن أكثر من "رد فعل على تتاقص المبيعات ومن أجل حل ظرفي لمشكلات البيع

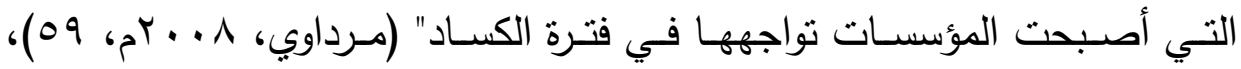
وواضـح مـن خـلال كتابـات الكثيـر مـن الاقتصـاديين أن اسـتخدام أسـاليب البيـع وتقنياته المختلفة كان سمة بـارزة في الاقتصاد الرأسمالي خـلال السنوات التي تلت أزمة الكساد، فمثنلا (Boltanski and Shiapello, 2005) في كتابهما "الروح الجديدة للرأسمالية" يقرران أن الروح الأولى للرأسمالية والتي برزت مـع نهاية القرن التاسع عثر ركزت على أهميـة الفرد المنظم، كما شهـت تطلعـات نحو مزيد من رفاه مشـترك يكـون أقـل اعتمـادًا علـى الليبراليـة الاقتصـادية حيـث آمنــت بـالتطور الاقتصـادي من خلال العلوم واستخدام التكنولوجيا وفوائد الصناعة...(p.17) (وهو ما يتوافق حسب رأينا مـع المفهوم الإنتاجي)، أما الروح الثانية فكانت بين عامي

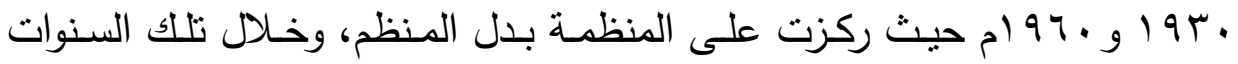

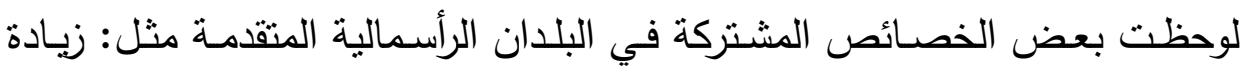
حجم الشركات، وهيمنة نظام الإنتاج الكبير الهادف إلى تحقيق وفرات الحجم حيث كان تتميط (توحيد) المنتوج هو النموذج المهيمن على طريقة العمل، كما شهدت 
تلك الفترة وبشكل واسـع استخدام تقنيات توسيع الأسـواق أي "التسويق".. (p.18) (وهو ما يتوافق مع حالة المفهوم البيعي).

إذن فقد كانـت أزمـة عـام 9 إم هـي الباعث على التحـول نحو الفلسـفة البيعية، ومنذ ذلك الوقت وحتى نهاية الخمسينيات فإن الفكر التسويقي بقي مرتبطًا بالمفهوم الإنتاجي والبيعي، رغم أن الكثير من الكتابات قبل ذلك بكثثر، ومنذ بداية القرن العشرين ركزت على أهمية المستهلك وعلى ضرورة الاعتراف بأن أنشطة المؤسسـة يجب أن تهدف إلى إثباع حاجاته ورغباته، فعلى سبيل المثنال شـاو

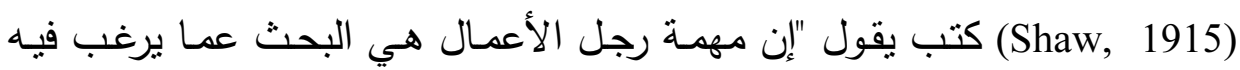
الناس وتوفير وسائل إثباع ذلك" (p.44) .. " إن الأساس الحقيقي للتبادل هو مدى

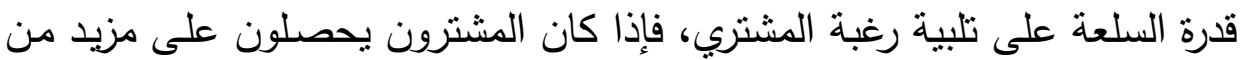
المتعة في مواصفات خاصـة لمنتجات معينة، فهي التي يجب أن ينتجها المصنع بـدل مواصفات يكون المشترون أقل رغبـة فيها، إنـه بـذلك يقدم خدمـة اجتماعيـة حقيقية في تزويدهم بما يرغبون فيـه" (p.48) .. "إن الغرض من إنتاج السلـع هو الإشباع وليس البيع" (p.82)، إن شاو (Shaw) يؤكد أيضًا على أن فعالية أنشطة التسويق مرتبطة بمدى التوافق مـع حاجات المستهلك " فإذا كانت السلعة المعلن عنها ليست مهيأة لتلبية حاجة ظاهرة أو خفية لدى المستهلكين، فأن الإعلان عنهات لن يكون ذا فعاليـة تذكر، إن محاولـة بيـع شيء لا أحد يحتاجـه هـي في حقيقة

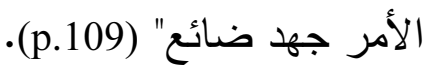

وعن أهمية دراسة سلوك المستهلك كتب (Copeland, 1923): "أولى الخطوات التي ينبغي للشـركة اتخاذهـا، هي القيام بدراسـة أوليـة لعـادات المستهـكين في شـراء منتجات من قبيل ما تتتجه الثركة" (نقلا عن: Svensson, 2005, p.08)، كذلك فإن (Ford and Growther, 1923) المستهلك أم العكس؟ إذا قرر المستهلك عدم الثراء، هل هو خطؤه أم خطأ الثركة؟ هُه هنه 
أم أنه لا أحد على خطأ.. في كل الأحوال النتيجة هي إفلاس الثركة، إن نجاح هذه الأخيرة موقوف فقط على قدرتها في خدمة المستهلك فيما يرغب فيه" (288.p)، وفي مقال حول كفاءة التسويق يؤكد (Philips, 1941) أن التسويق يجب أن يهدف إلى الى إثتباع الرغبـات الإنسـانية وأن أي دراسـة حول كفاءة التسويق يجب أن تتطلق مـن تلك الرغبـات "إن نظامنـا التسويقي سيكون ذا كفـاءة فقط حينمـا يقدم أعلى إثـباع للمستتهلك" (p. 360).

هذه بعض الأمتلـة عن الكثير مـن الكتابـات التي كانت تؤكد على الدور المحوري الذي يجب أن يحظى بـه المستهلك في العملية التسويقية، ومـع ذلك فإن

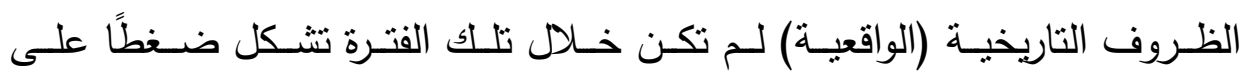
المؤسسات لكي تسمح لحاجات المستهلك بلعب ذلك الدور في الواقع العملي، هذه الوضـعية تغيرت فقط مـع بدايـة الستينيات حينمـا واجهت الرأسـمالية (خاصـة في

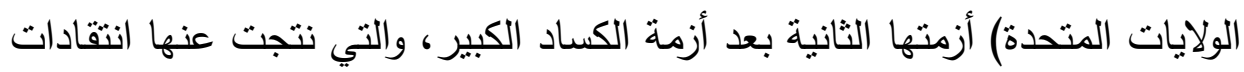

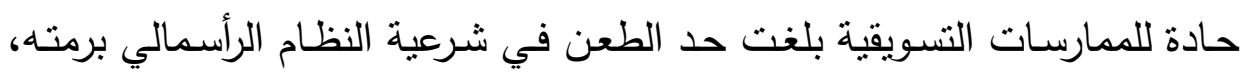

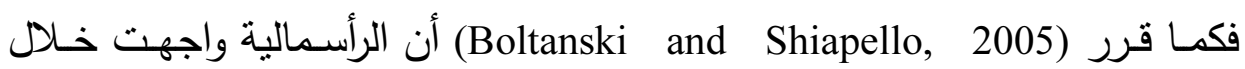

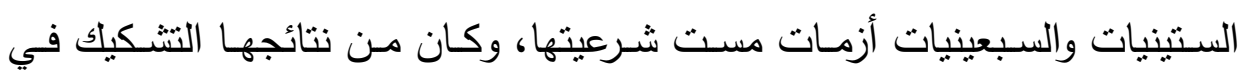
النظـام الأخلاقي للمجتمع الرأسمالي، ليس فقط مـن طرف المتخرجين والعـاملين المؤهلين الذين وجدوا أنفسهم عاطلين على أرصفة شوارع باريس ولندن ونيويورك.

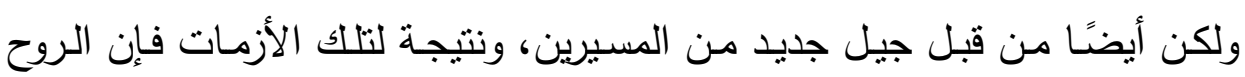
الرأسمالية المطبوعة بقيم العمل التقليدية: الإنتاج الكبير ، والبيروقراطية الإداريـة، والتخطيط طويل المدى.. قد تم تجديدها واستبدالها بروح أخرى متشبعة بقيم ذلك الجيل الجديد: الحريات، والرغبات الفردية، والمساواة.

ومن وجهة نظرنا فإن التسويق لعب دورًا حاسمًا في تلك العملية التجديدية أو على الأقل كان لله إسـهام بـارز في ذلك من خـلال إضـفائه مزيدًا من الثـرعية 
الأخلاقية على مؤسسات الأعمال، وباختصار فإن تحليلنا لأدبيات التسويق يظهر أن إرضاء رغبات وحاجات المستهلك أصبح جزءًا مهما من المناقنـات الأكاديمية والتطبيقات العملية فقط مع نهاية الستينيات، هذا التحول يمكن أن نفهمه كرد فعل جل مباشـر على الانتقادات القويـة الموجهة للتسويق وللرأسـمالية بصفة عامـة، حيث مست شرعيتها بعمق، ما نود قوله أنه وخلال أزمـة الستينيات لعب التسويق دورًا

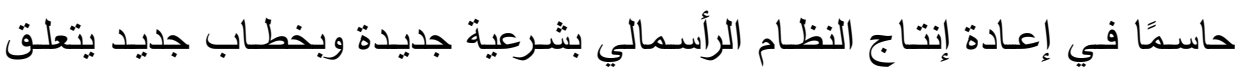
"بإثباع حاجات ورغبات المستهلك".

ففي بحث فلسفي تاربخي توصل (Brei and Böhm, 2008) إلى أن "هناك افتقارا في قلب الرأســـالية، افتقارا إلى المعنوبـات (Moral) وإلـى نظـام أخلاقي ومعياري من شـأنه أن بضفي الثـرعية على التراكم الرأسمالي بعيدًا عن الثكليات

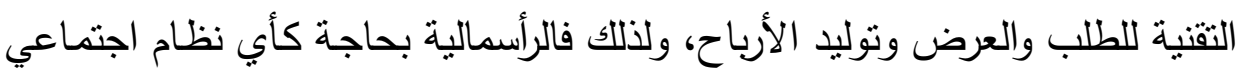
واقتصـادي إلى هذه الثرعية من أجل إعادة تجديد ذاتها في مواجهة حدود الزمان والمكان" (p.10)، وفي رأيهما فإن فترة الستينيات قد شهدت تحولاً حاسما في الطريقة التي تضفي بها الرأسمالية الثرعية الأخلاقية على نفسها، حيث كتبا "إن التغيير في الخطـاب التسـويقي مـا بـين • 197 و • 9 أم يظهر طريقـة تكيـف الرأسـمالية مـع الظروف المتغيرة، حيث كانت مهمة التسويق هي إيجاد طرق جديدة من أجل بيع المنتجات والخدمات والأهم من ذلك إيجاد أسـاس جديد لشرعية النظام الاقتصادي القائم .. لقد قام التسويق خلال أزمة الستينيات بهذه المهمة من خلال التأكيد على تلبية احتياجات الأفراد ورغباتهم، لقد استطاع الفكر التسوبقي إدماج القيم الاجتماعية للحركات المناهضـة والمنتقدة عن طريق إعادة تشكيل وتعريف المنتجات والخدمات بوصفها تعبيرًا عن الرغبات الفردية.. لقد بدأ عصر سيادة الفرد ورغباته، إنها روح جديدة، لقد تم التغلب على تلك الأزمـة بروح جديدة من الرأسـمالية من شـأنها أن تجعل الناس بذهبون إلى المحلات التجارية مرة أخرى" (12-10). 
غير أن تلك الروح الجديدة مـا لبثت أن واجهت أولى العقبات مباشرة في

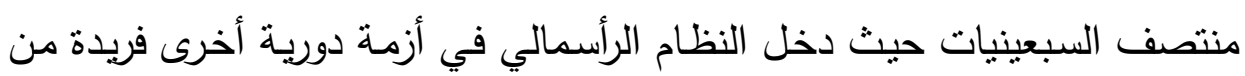

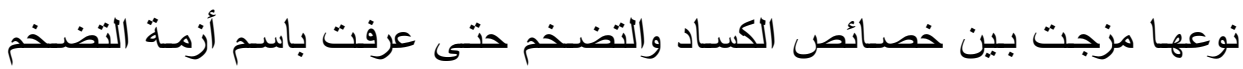

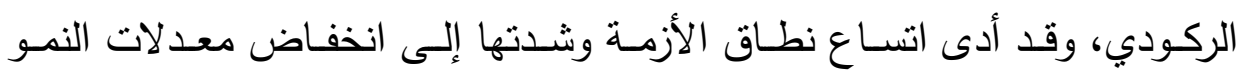

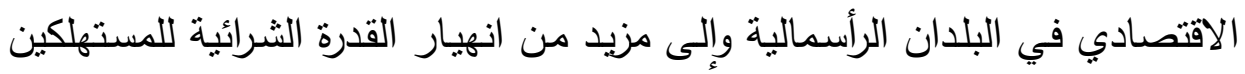

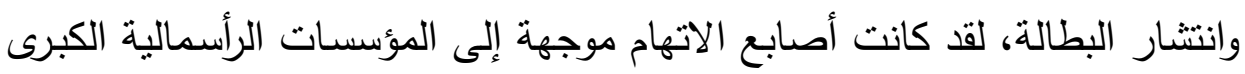

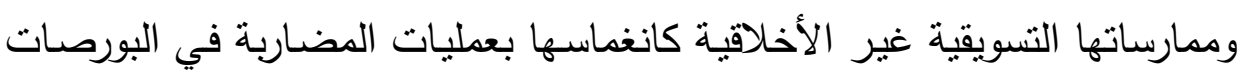

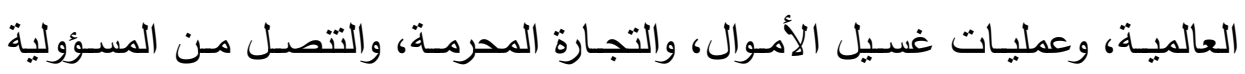

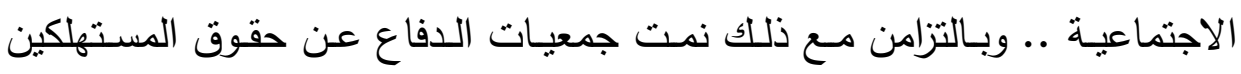
ومنظمات حماية البيئة والتي رأت "أن موارد الدجتمع يتم استنزافها، وأن البيئة التي

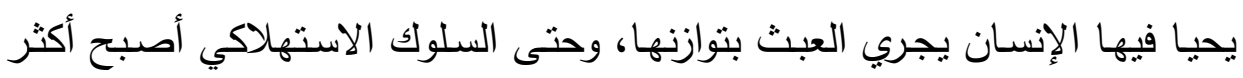

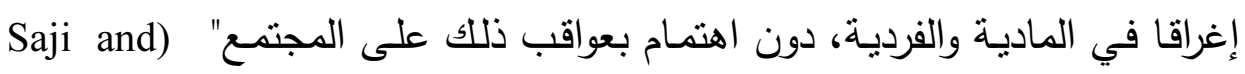
.(Mukundadas, 2007, p.507

كل ذلك كان له آنار واسعة في مجال التسويق حيث قاد إلى مناقثات حادة

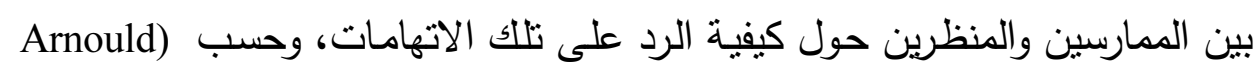

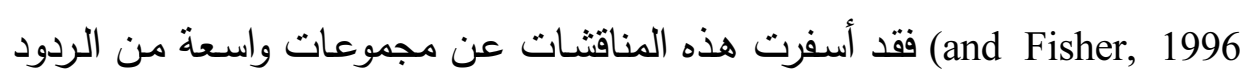

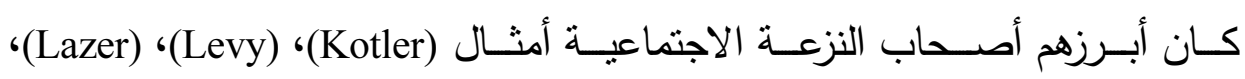

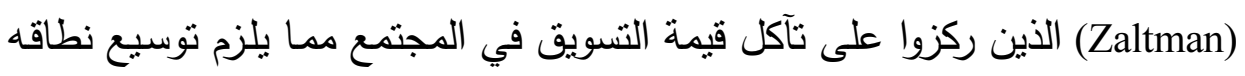

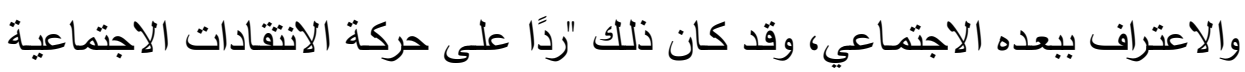
التي نزعت الثرعية عن النظام الرأسمالي في تلك الفترة". لقد جـاءت هذه التغيـرات نحـو أهميـة المجتــع ورعايـة مصـالحه (المفهوم

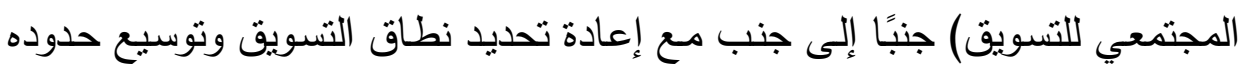

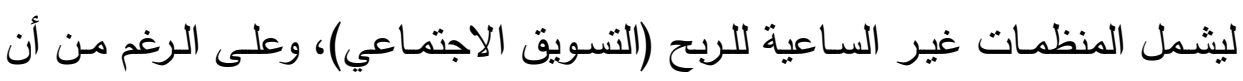


بعضهم عارض هذا التوسيع إلا أنه أضحى جزءًا من أدبيات التسويق المتقق عليها

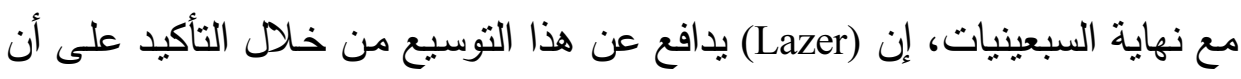
نقد التسويق كان بسبب افتقاره إلى المساهمة في حل المشاكل الاجتماعية ووفقا له فـإن التغيـرات فـي نطاقـه لابــد منهـا لتبريـر دور التشـويق فـي اسـتمرارية النمـو

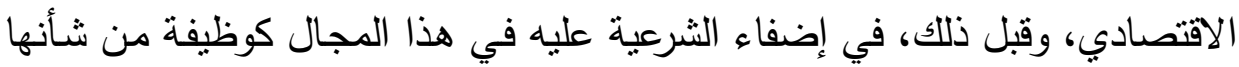
أيضًا أن تتظر في "أهداف المجتمع" (Lazer, 1969, pp:3-9). وخلاصــة الأمـر أن الفلسـفة التسـويقية كانـت دائمَا فـي تغيـر مسـتمر وأن الأزمـات الاقتصـادية التي مـر بها النظام الرأسمالي كانت سببا مباشـراً في ذلك التغير، ذلك أن التسويق لعب دورًا رئيسيًا في ضمان استمرارية شرعية الرأسمالية، والثيء الثابت أن هذه الثرعية كانت دائمًا ولا زالت تحت تهديد مستمر ، تحديدًا

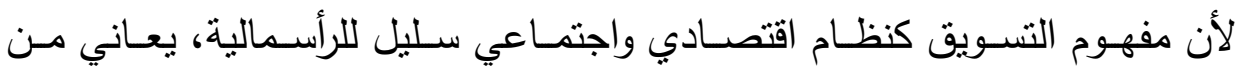
الافتقار (Lacking) في الأسس التي يقوم عليها، لقد ثبت في واقع الحال أن تبني التسويث الحديث فلسفة وأداء وإن لعب دور مسكن للألم إلا أنه لـم يوقف تكرر الأزمات الاقتصادية ومعاودتها بشكل دوري، فها هي الأزمة الأخيرة -أزمة الرهن

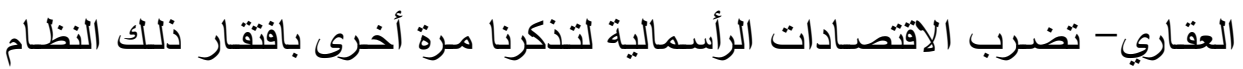

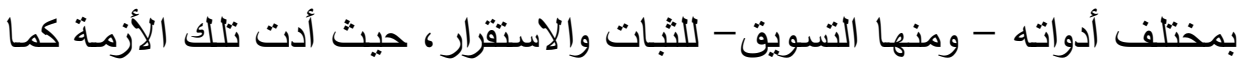
قرر (Martine et Loubat, 2010) "إلى موجات جديدة من المتطلبات الأخلاقية، فضحاياها هم من الفئات التي تضررت حديثا من التجاوزات الأخلاقية للشركات والمؤسسـات،.. إنـا نعتقد أن الخروج مـن الأزمـة يجب أن يحمـل أبعادًا أخلاقيـة جديدة" (p.04)، وكذللك كتب (Varey, 2011) بعد الأزمة مقالا أنحى فيه باللائمـة على النظام الغربي الذي يقوم حسب رأيسه على سيادة المنفعة الفردية ودافع الربح

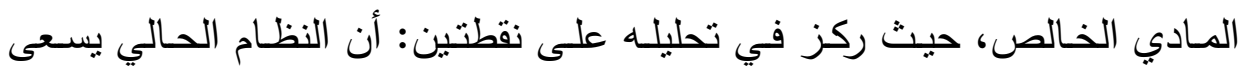
أكثر من أي وقت مضى إلى توسيع النزعة الاستهلاكية والإنتاجية غير المستدامة وسوف ينهار في نهايـة المطاف، وأن هناك حاجة ضرورية إلى الـى نظام جديد يقوم 
على أساس واحد وهو مفهوم "تسويق الرفاه الاجتماعي"، حيث يكون دور التسويق هـ تعزبـز الاسـتدامة وليس زيـادة النــو، وتوفير الحاجـات ولـيس مجرد البيـع، وبالنهاية فإنه يدعو إلى إعادة صياغة دور التسويق في المجتمع. وتبعًا لذلك فقد برزت إلى السطح مفاهيم جديدة لتقوم بذات الدور الذي قامت بـه المفـاهيم السـابقة، ومنهـا: التسـويق الإنسـاني، والتسـويق الأخلاقي، والتسـويق

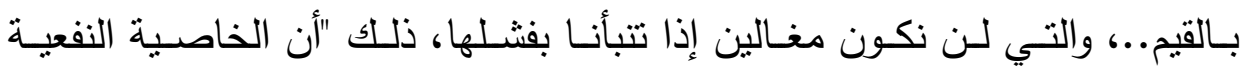
والمصلحية التي تقوم عليها عملية المبادلة" والتي يتميز بها المفهوم التسويقي في شكله التقليدي والحديث والمطور قد جعلت التسويق يخفق بل يعجل في حصول مثنل هذه الأزمات،ه.. لقد عجز المفهوم التسويقي الحديث والمطور عن التعامل بإيجابية مـع الأزمات الدوريـة التي يفرزها النظام الحر، نظام اقتصـاد السوق، في كل مرحلة من مراحل تطوره، بل لقد كان لهذا المفهوم دور المغذي للأزمة المالية

" هذه الخاصية ليست محض فرية ولكنها واضحة في كتابات الكثير من الباحثين حيث يفترض الفكر

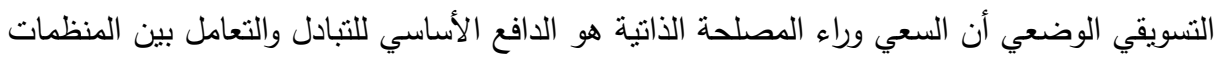
وجمهورها، فهذا (Bagozzi) يقرر بوضوح دافع المصلحة الذاتية في سياق التسويق، عندما كتب البيان

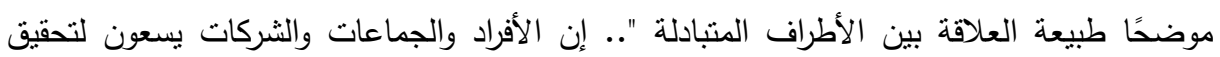
المصلحة الذاتية وهذا هو ما يعنيه آدم سميث حين أثنار لليد الخفية.. إن التبادل والسعي وراء

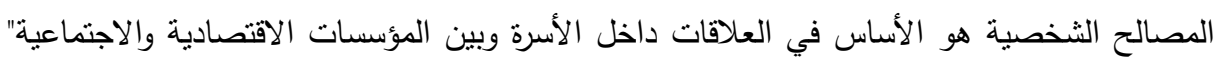
(Bagozzi, 1975A, p.34)، وفي مقاله "التبادل الاجتماعي في التسويق" كتب أيضا: "إن نموذج التبادل الاقتصادي مبني على مبدأ النفعية الذي يعني أن الأفراد بسترشدون في سلوكياتهح بالمصلحة الذي الذاتية

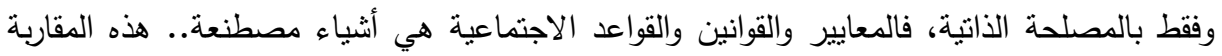
تفترض أن الجهات المنبادلة تسعى لتحقيق أكبر إثباع من خلال المبادلة، المؤسسة تراه أقصى ربح ممكن، في حين أن الفرد يسعى لأكبر منفعة ممكنة" (Bagozzi, 1975B, p.316)، هذا التسليم يدافع عنه النه أحد أقطاب الفكر التسويقي (Shapiro, 1973) الذي يؤمن هو الآخر بالدور المركزي لمفهوم المصلحة الذاتية في التسويق فيقول "لن أكلف نفسي عناء مناقشة هذا المفهوم، حيث يمكن أخذه كأمر مسلّم به" (D.124))، وكذللك (Doyle, 2010) "إن البائع والمشتري بطبعهما مدفوعان نحو مصالحهما الذاتية..

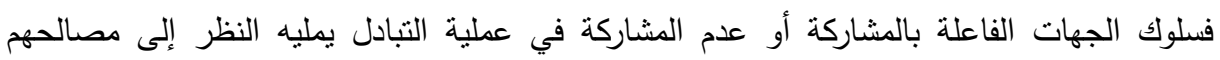

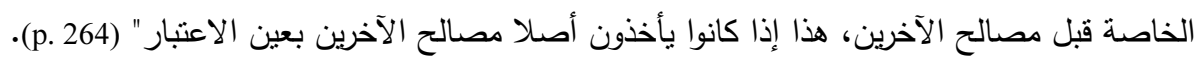


الراهنـة، كمـا كـان لمفهـوم التسـويق التقليـدي دور الموقـد للأزمـات الاقتصـادية السابقة، لما يقوم عليه هذا التسويق في - شكله التقليدي والحديث والمطور - من مرتكزات نفعيـة ومصلحية، وإن بدت في مفهومـه الفلسفي الحديث معاني الترويج لتبادل المنـافع والحرص على تحقيق مصلحة أطراف المبادلة، البـائع من جهة،

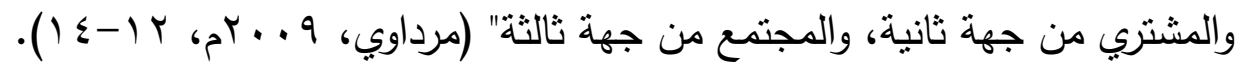

ومن خلال التحليل السابق يمكن أن نخلص إلى أن جميع المفاهيم التسويقية الوضعية لم تقم على عقيدة أو مذهب فكري أو مبدأ أخلاقي في الأساس، وإنما كانت نتاجا للواقع التاريخي الذي أشرنا إليه واستجابة لتقلبات الظروف والأحوال، وأن تطور الفلسفة التسويقية كما قدمناه يشير إلى افتقار النظام التسويقي الوضعي إلى خاصية مهمة وهي التبات والاستمرار ، حيث إن مفهوم التسويق بكافة مراحله قد نشأ في ظروف وبيئات معينـة وليس وفق أسس ثابتة، فهو إذن لا يصلح حسب رأينا- للتطبيق إلا في تلك الظروف والبيئات، أضف إلى ذلك أننا نلمح في ثنايـا تلك الفلسفة تخبطـا في تحديـ محسور النشـاط التسـويقي، مـن خـلال تعـدد

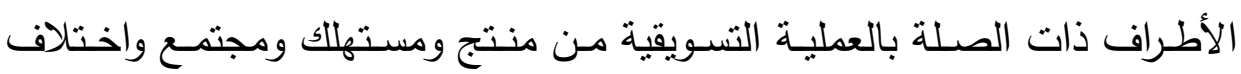
أهداف كل طرف، حيث أدى هذا التعدد وذلك الاختلاف إلى تعارض مصالح تلك الأطراف ومحاولة كل منها تغليب مصلحته مع كل مفهوم من مفاهيم التسويق بدءًا بالمفهوم الإنتاجي ومرورا بالمفهوم التسويقي وانتهاء بالمفهوم المجتمعي. تلك كانت بعض الأسباب التي حدت بالكثير من علماء التسويق الوضعي كما رأينا- إلى التأكيد على أن هنالك حاجة لإيجاد نموذج جديد، وإن لم يتم التعبير بصورة كاملة عن الصيغة التي قد يأخذها ذلك النموذج، وهذا ما يوصلنا إلى اقتراح ومناقثة نموذج التسويق الإسلامي من أجل استحداث مفهوم جديد يمكن أن يشكل أساسا لممارسات تسويقية مستتدة إلى قيم وأخلاقيات الإسـام الراسخة وإلى قواعد فلسفته المعنوية الثابتة. 


\section{المبحث الثاني: مفهوم التسويق في الروئية الإسلامية}

يتطلع كل نظام اقتصادي واجتماعي إلى تحقيق أهداف معينة (مادية كانت أو معنوية)، تلك الأهداف إنما يستلههها ذلك النظام من القيم الفلسفية والأخلاقية والدينية والقانونية التي يدين بها المجتمع، ذلك أن النظام الذي يرتضيه المجتمع النع لنفسه ينمو عضويا من معتقد الإنسـان عن الكون والحياة ووظيفة الإنسان فيهما، ولا يمكـن دراسـة أي نظـام اجتمـاعي أو اقتصـادي بمعـزل عـن جـوره العقديـة والفلسفية، إذ هو جزء لا ينفصم من النظرة الكلية للأشياء والتي استقرت في وجدان المجتمع، من أجل ذلك فإن فهما جيدا لمفهوم التسويق في الإسـلام لا يتأتى إلا عن طريق دراسة منطلقاته الفكرية الفلسفية وأصوله المبدئية.

\section{المطلب الأول: القلسفة التسويقية في الإسلام}

لاشك في أن خلو التسويق فلسفة ونشاطًا من القيم الثابتة والمبادئ الأخلاقية

قاد إلى مشاكل معقدة ومستعصية، ولذلك فقد أصبح هناك اعتراف واضح وصريح مـن رواد الفكر التسـوبقي الغربـي وفلاسـفته بضـرورة أخذ الأخـلاق ومراعـاة القيم كمدخل أساسي في مفهوم التسويق (نظربة وتطبيقًا)، لقد أطلق (Kotler) وبالتعاون مع الباحث التسويقي المسلم (Kartajaya) نظريته الجديدة في التسويق والتي سماها

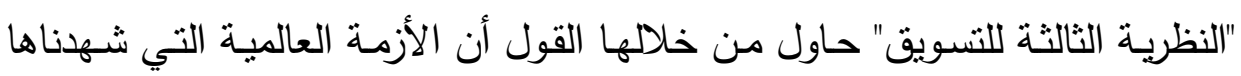

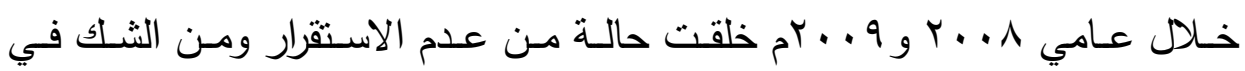
الأسس التي يقوم عليها الاقتصاد الغربي، وأن ما حدث كان بسبب انتفاء التعاملات الإنسانية في سوق المال، حيث تركت دون قيم ومبادئ أخلاقية تحكم التعامل "..إننا نشهد في نظرية التسويق الثالثة عصرًا تحركه القيم، فبدلاً من معاملة الناس كما لو

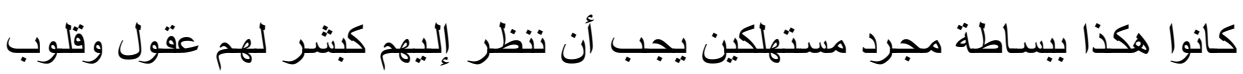
وأرواح، .. إن البشر في هذا العصر ييحثون على نحو منزايد عما يلبي رغباتهم 
العميقة في العدالة الاجتماعية والاقتصادية والبيئية... إنهم يتطلعون إلى الوفاء ليس فقط بحاجاتهم المادية والعاطفية ولكن أيضـا بحاجاتهم الروحية من خلال المنتجات والخدمات التي يختارونها" (Kotler, et al., 2010, p. 04).

وإذا جاز كوتلر وآخرون (Kotler, et al., 2010) أن يقول متحدثا عن نظريته "حين وضعت نظريتي الجديدة "التسويق الثالث" من خلال القيم والمبادئ لم أكن اعرف كثثرا عن الإسـام ولكني اكتشفت أن النظريـة التي وضـتهها كانت مبنيـة على أسس الثربعة الإسـلامية والتعاملات في الدين الإسـلامي.. وهو مـا يعكس تكـاملا بين نظريتي الجديـدة ومـا جـاء بـه الـدين الإسـلامي في التعـاملات بين الناس"(*)، وبغض النظر عن أي تعليق حول هذا الكلام فالحقيقة التي ربما يدركها أن المشـكلة ليسـت في "التسـويق" وحـده ولكنهـا في مرتكـزات النظـام الرأسمالي نفسه، ولذلك فإننا نعتقد أن " التسويق الذي يحلّ الأزمـة ولا يقود إليها هو التسويق الذي تحكمه ضوابط وتوجّهه قيم، ولا يوجد مثل هذا التسويق القيمي إلاّ في نظام اقتصـادي يقوم بدوره على قيم وتحكمسه ضـوابط تراعي بحقّ ودون

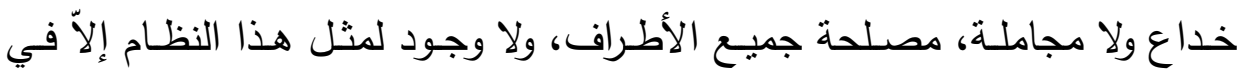
الإسلام، كما أنّه لا وجود أيضـا لمثل هذا التسويق القيمي الذي يحقّق بدوره، دون تضليل أو خداع أو تغرير أو تدليس أو تزوير أو غشّ أو مضاربة، مصلحة جميع الأطراف، إلاّ في هذا النّّام الاقتصادي الذي يقوم على مبادئ الإسلام" (مروادي،

$$
.(10 \text {, } 10.9
$$

وفي الواقع فإنه لا يوجد معتقد ديني منفصل تماما عن واقع الأنشطة اليومية للبشر ، السياسية منها والاجتماعية والاقتصـادية، " فالعلاقة بين الروحانيـة والحياة

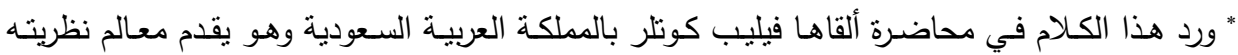

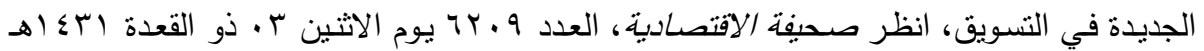

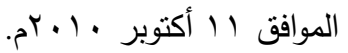


الاقتصـادية لا يمكن تجاوزهـا.. إن الروحانيـة والدين جزء لا يتجزأ مـن الأنشـة الاقتصـادية" (Kale, 2004, p. 97)، وكـذلك فـإن أتثر التـدين علـى السـلوكيات التسويقية هو أثز واقعي، ذلك أن العديد من الناس يستمدون الأحكام الصسادرة عن وكن صواب أو خطأ أعمالهم من مصسادر دينيـة وبينون فلسفتهم الأخلاقيـة الثخصية دونية عليها (Anusorn, et al., 2000)، وبالمثنل فإن التعاليم الإسـلامية تشـل جميع

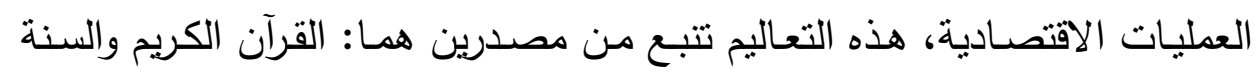

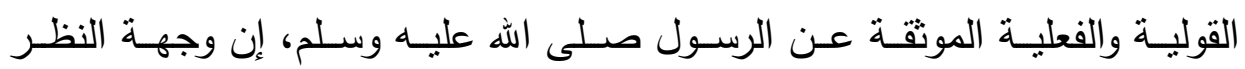
الإسـامية في هذا الصـدد، تجد جذورها الراسـة في مبادئ العدالـة والإنصـاف، حيث توفر السبل والوسائل الكفيلة بخلق القيمة ورفع المستوى المعيثي للأفراد من خـلال النشاط التجاري الملتزم بتلك المبادئ، والجدير بالذكر أن معالجـة الإسـام لهذه القضايا متميزة عن غيرها تمامًا، وخاصة في هذا الجانب من النشاط البشري وذلك بما يلي (Saeed, et al., 2001, p.128):

أولاً: أن الإسـلام لا يعترف بأي انفصـال بين الأبعاد الدنيويـة والروحيـة، ذلك أن الفرد في هذا الإطار يسعى لإرضاء ربه من خلال اتباع أوامره واجتتاب نواهيه التي تتخلل جميع جوانب الأنشطة الحياتية (الدنيوية) لهذا الفرد.

ثانيَّا: أن كل سـي إنسـاني بمـا في ذلك النشـاط الاقتصسادي يشكل جزءًا من عقيدته الدينية انطلاقا من علة وجوده كمخلوق في هذه الأرض، وبعبارة أخرى فإن كل شيء يقوم به الإنسان يجب أن ينبثق عن إيمانه بوظيفته كعبد لخالق واحد. ثالثًا: في الإسلام، يعتبر كل نشاط تجاري (بما في ذلك التسويق) على قدم المساواة مع أي شكل آخر من أثكال العبادة. ويترتب على ذلك أن كل فرد في حياته كلها يعتبر مسؤولا عن جميع أنشطته

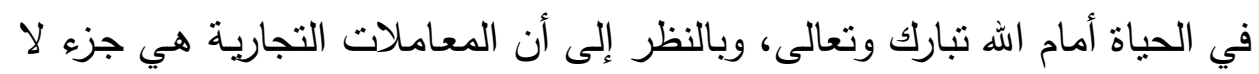


يتجزأ من حياة الناس اليوميـة فإن الإسـام ينظر إليها على أنها أعمال يجب أن تؤدى وفقًا للقوانين والتعاليم التي جاء بها.

فليس من المستخرب إذا أن نعلم أن مبادئ التسويق الأخلاقيـة والقيميـة تلقى اهتمامـا خاصسا في الإسـام، حيث تشكل أدبيات نظريـة مستقلة تدعمها الممارسات

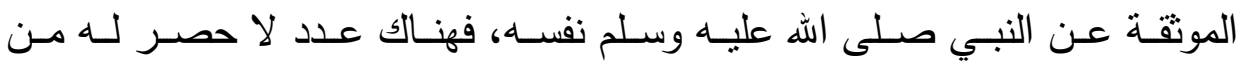
النصوص التي توثق تلك الممارسـات فيما يتعلق أساسًا بالمعاملات التجاريـة التي توفر نظامًا قيميًا عمليًا لسـلامة اتخاذ القرارات التجاريـة، الأمـر الذي يسـهل وضـع إطـار صـارم ومتكامـل لتصــنيف وتقيـيم السـلوك التسـويقي كجـزء مـن الســوك الاقتصـادي العام، " فقد اهتم الإسـلام قديمًا ولا يزال بالقضـايا المتعلقة بعملية الثراء والبيع وعلاقات التبادل، وحرص على تتظيمها بما وضعه من مبادئ وأسس تحافظ على سلامة هذه العمليات دون جور طرف على آخر، وبما ينعكس أثره على رفاهية

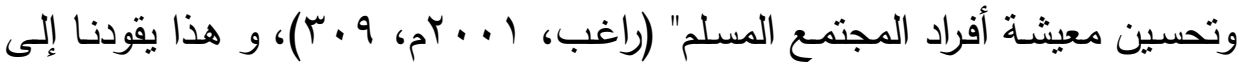
الحديث عن مفهوم الاقتصاد الإسلامي وتعريفه بشكل يفصح عن مكوناته الأساسية ويعطينا تصورًا عامًا عن النظام الكلي الذي يشكل التسويق جزءًا منه، لقد عرف بعضهم الاقتصاد الإسلامي بأنه "مجموعة الأصول الاقتصادية العامة التي تستخرج

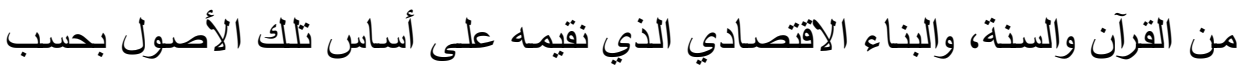
كل بيئة وكل عصـر" (العربـي، ص اب)، حيـث يمكن أن نقرر مـن خـلال هــا التعريف أن مكونات المنظور الإسلامي قسمان: أحدهما ثابت والآخر متغير . الثابت: هو ماله خاصية الثبات، وهي تلك القواعد الاقتصادية المستتبطة من الكتاب الكربم والسنة النبوية، وهذا ما يطلق عليه "المذهب الاقتصـادي" أي الأصسول

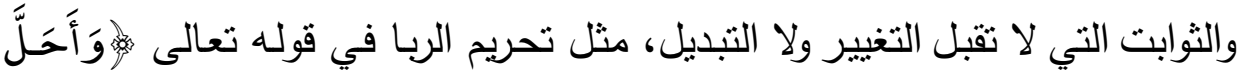

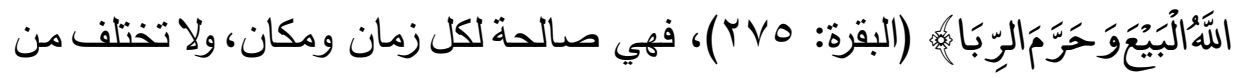


بيئة إلى أخرى وهذا الثبات لا بعني أن هذه الأصول العامة للفقه الاقتصادي جامدة لا تسع ما يستجد من الأمور ولكن هذا فقه ثابت في أحكامـه لما هو معروف فقط

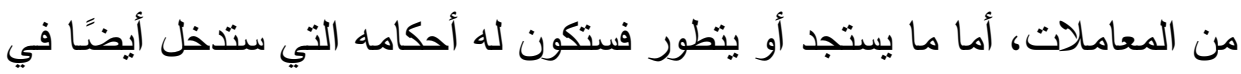

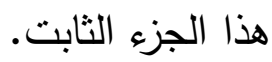

المتغير: هو ماله خاصية التطور ، وهو البناء الذي يقوم على أساس الأصول الثابتة، أي تلك الممارسات العملية والحلول الاقتصادية التي توصل إليها المجتهدون تطبيقا للمبادئ السابقة، وهي ما يطلق عليها "النظام الاقتصادي" وهي من المتغيرات التي تتبدل باختلاف الزمان والمكان، وبتغير البيئات والظروف التي تطرأ من آن إلى آخر ويدخل تحت هذا ما يتعلق بالأدوات التي يمكن أن يعمل بها اقتصـاد "يسير

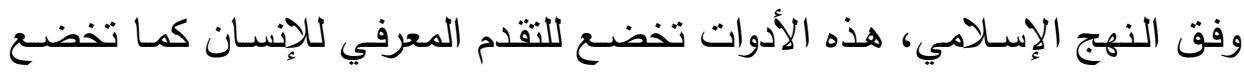

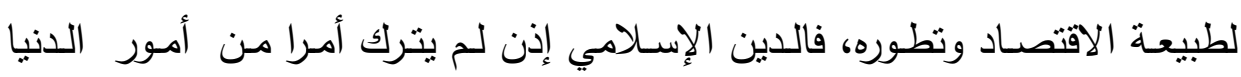
والآخرة إلا وجعل له المبادئ العامة التي تحكمه، هذه الأخيرة لا تتضمن أحكاما

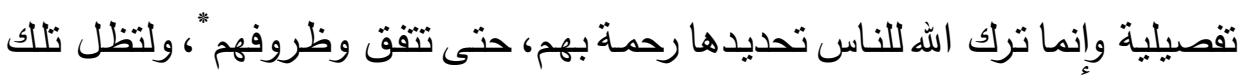
المبادئ صالحة للتطبيق في كل زمان ومكان.. فالأعمال الجزئية كأنشطة التسويق

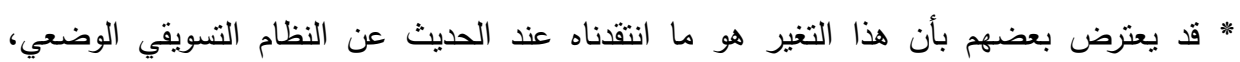

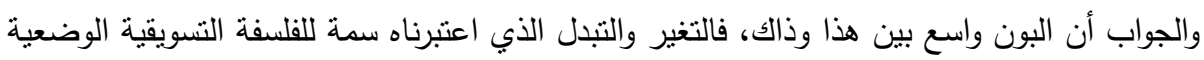

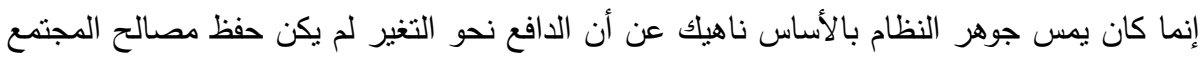

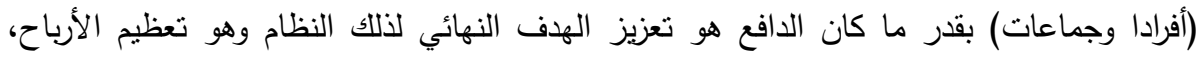

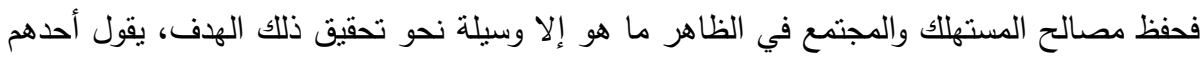

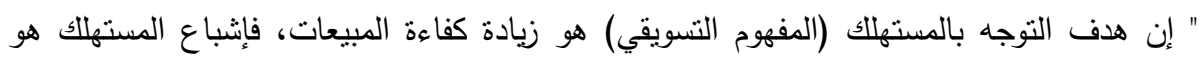

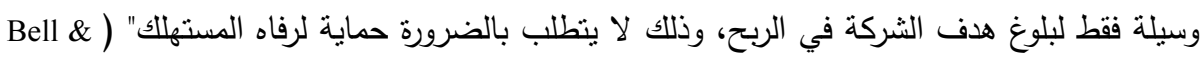

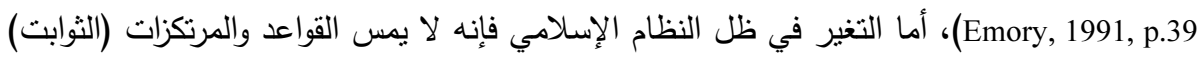

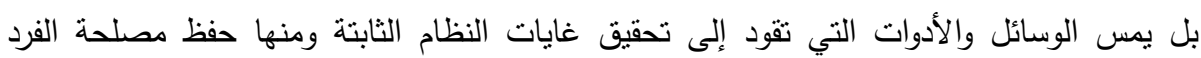
والمجتمع معا، إن هذه المصلحة هي هدف ثابت وليس وسيلة تتبدل وتتغير . 
ومهام المسوّق جعل لها أحكاما عامة تضبطها في مختلف مراحلها" (بلحيمر،

$$
.(r \leq 6, \quad .0
$$

إذن وانطلاقا من القواعد الثنابتة والحلول المتغيرة التي تحكم النشـاط التسويقي وفق التصور الإسلامي، يمكن أن نقرر أن الفلسفة التي يقوم على أساسها التسويق الإسـامي تستتد إلى طبيعـة هذا الدين كنظام كامل للحياة يحدد للإنسـان أهدافه الأساسية ووظيفته في هذا الكون، وكما ذكر محمد بهجت (ع 99 (م) فإن أهداف النشاط الاقتصادي تتمنل في الآتي:

ابتغاء الدار الآخرة: وذلك لا يتحقق إلا برضـا الله عز وجل والذي ينتج بـدوره عـن الالتزام بـأوامره واجتتـاب نواهيـه، وهـو مـا جـاءت الثـريعة الإسـلامية لتوضيحه.

(r) تحقيق عائد للفرد من خلال استثماره لأمواله، وتملكه لعناصر الإنتاج، بما يضمن له ولمن يعول حياة إنسانية كريمة.

الإحسان من خلال المال الذي أعطاه الله إياه بالإنفاق منه على الآخرين وعلى المحتاجين ونشر دعوة الله في الأرض، والإحسان كلمة جامعة لكل معاني • الخير

(ع) عـدم الفسـاد فـي الأرض مـن خـلال الرثـوة وتلويــث البيئـة الطبيعـة والأخلاقية للمجتمـع من أجل تحقيق الربح وهي السلبيات التي نتجت عن النظام الرأسمالي بسبب تبريره لهذا السعي نحو تعظيم الأرباح.

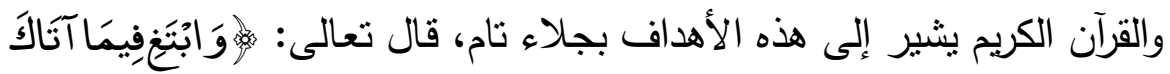

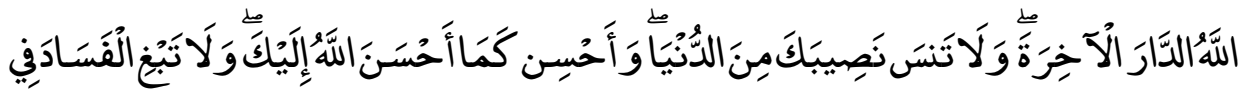

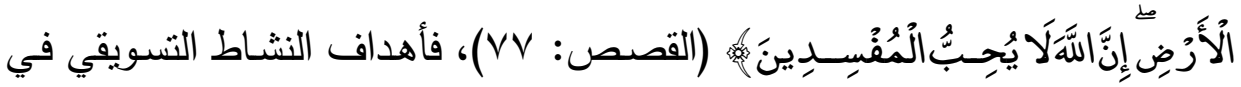


الإسـام لا تتحصر على تعظيم الأرباح للمنتج ولا على إثباع رغبات المستهلك أو مراعاة مصلحة المجتمع بشكل يوحي بتضـارب للمصـالح، ولكن التسويق الإسـلامي يؤكد على تعظيم القيمة من خلال توليفة متوازنة بين الأبعاد المادية والروحية للحياة، فإنثباع الرغبات الإنسـانية يخضـع للتوجيهات والتشـريعات الإسـامية التي تقود إلى تعظيم رفاه البشرية في الدنيا وفي الآخرة، وتؤسس لأخوة حقيقية بين جميع أصحاب المصلحة فضـلا عن بسط العدالـة الاجتماعيـة والاقتصـادية في كل شـعب الحيـاة الإنسانية (Mahboub and Shariful, 2011).

\section{المطلب الثاني: الأصول العامة لمفهوم التسويق في الإسلام}

إن أصول وأسس النظرية التسويقية الإسلامية يمكن تلخيصها في ثناثة أسس تحكم الفرد والمجتمع، وهي:

أولا: الأســـاس العقائـــي: إذا انطلقتـا مـن فهمنـا للتقاليـــ التوحيديـة الأخـرى كالمسيحية منثلا وقبولها بمبدأ المصلحة الذاتيـة ومفهوم سيادة السوق، والتي نالت مشـروعيتها من خـلال كتابـات آدم سميث في ثروة الأمم، حيث تم اعتبـار تطبيق القواعد الروحيـة والنصـوص الدينيـة على المعـاملات الاقتصـادية في المجتمعـات المسيحية العلمانية عاملا يضع التمية الاقتصادية تحت الرقابة غير المشروعة لمثالية الأديان، فإن هذا الفصل هو ما لا نجده في التصور الإسـامي الذي يستتد إلى أن الخلق كله مـن الله وحده، فـالله لـم يخلق هذا الكون كعـالم طبيعي لمجرد الإيجـاد فحسب، ولكن ضمن إطار مهمة وغرض محددين، إن وحي الله (قوانينه وتوجيهاته) يجب أن يحكم نظام الخلق كله، والأنشطة البشرية مهما كانت يجب أن تتسق مع هذا النظام ففي صميم الروئية الإسـلامية المتميزة نجد مفهوم "التوحيد" وهو الحقيقة الإلهية التي يكثف عنها القرآن الكريم (Gibbs \& Ilkan, 2008, p. 165). 
فاللتوحيد هو حجر الأسـاس في الدين الإسـامي وعليه تقوم النظـرة العامـة للحياة وكل شيء آخر ينبثق منه بصورة منطقية (Rice, 1999, p.347)، كما قال

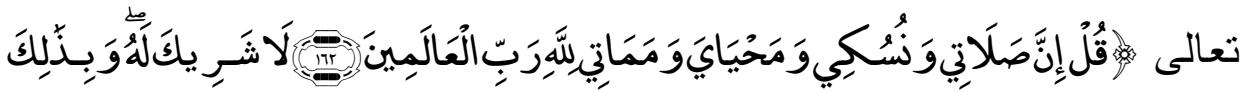

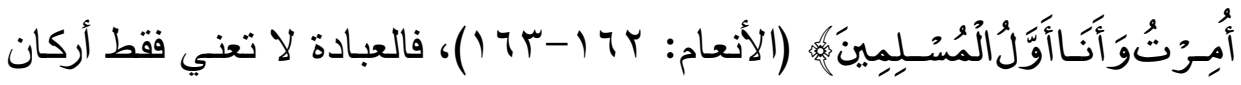
الإسـام الخمسة ولكنها تشمل أيضـا من بين جوانب أخرى للحياة: الأكل والنوم، ودراسـة الكون وكذللك ممارسـة الأعمـال التجاربـة .. كمـا تتضــن السـعي لكسـب المال الذي يعيل الأسرة.. إن جميع المساعي والأنشطة البشرية ما دام القصد منها هـو تحقيق مرضـاة الله هي جـزء مـن العبـادة، فالتعـاليم الإســلامية تشــل جميـع العمليات الاقتصادية بما في ذلك التسويق سواء على المستوى المحلي أو العالمي" (Saeed, et al., 2001, p.138) إن الثهادة وهي الركن الأول من الإسـام تشكل مفتاح مفهوم التوحيد، والثهادة هي الاعتراف والإيمان المطلق من الإنسان بخالقه

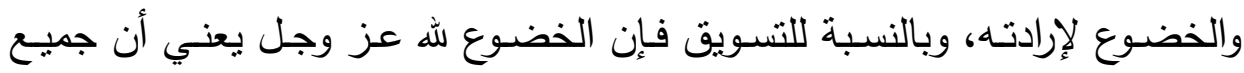

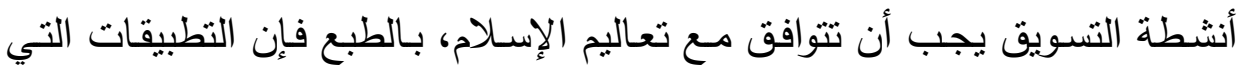

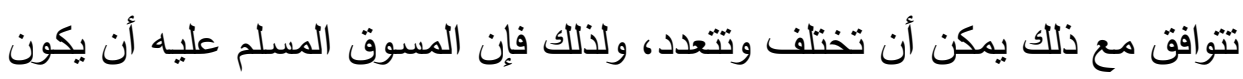
مسـتعدا وقـادرا على إدراج روح الإسـاحم في جميـع جوانـب العمـل التسـيقي مـن التخطيط إلى خدمات ما بعد البيع (Arham, 2010, p.152).

ثانيا: الأسـاس الأخلاقي: إذا كان بعض مفكري التسويق الوضعي يعترفون

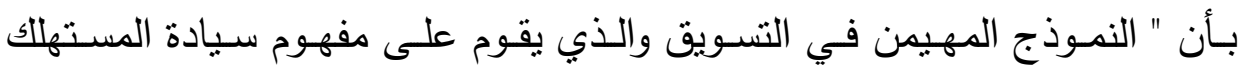
يفترض أن دور العملية التسويقية في طبيعته تقني وليس أخلاقيًا، حيث إن الهدف منـه هو تحويـل الطلب إلى إنتاج وليس الحكم على مـا هو الطلب أو الإنتاج الأفضل (أخلاقيا واجتماعيا) (Crane \& Desmond, 2002, p.548)، فإن المنظور الإسـامي لا يعترف بـأي انفصـال بـين النشـاط الاقتصـادي بصـفة عامسة وبـين 
الجانب الأخلاقي سواء من حيث الوسائل أو من حيث المقاصد والغايات، فأخلقه التسويق مفهوم مستمد من الاقتصـاد السياسي الإسـلامي حيث إن مفهوم الأخلاق Choudhury, 2000, ( يتعين "إجراؤه على جوانب الاستهلاك، والإنتاج، والتوزيعي" 26)، فالإسلام يؤمن بالميل الطبيعي للإنسان نحو المثل العليا ومع هذا السياق فإن نشوء نظام أخلاقي تسويقي، يمثل الأبعاد الروحية الثابتة لوجود الإنسان والتي لا يمكن تجاهلها تماما.. وغياب تلك الأبعاد يعكس انحرافات وتتوهات في طبيعة لتهن الإنسـان وهي نتيجة للتفاعل داخل بيئة خارجية غير أخلاقية تطمس مـع مرور الزمن كل تفكير عقلاني وتسـل الميل نحو الممارسـات اللأخلاقيـة في التسويق .(Saeed, et al., 2001, p.130) كما أن مقاربة أخلاقيات التسويق في الإسـام تختلف عن المقاربة الوضعية في عدة نواح منها: - أنها ليست نسبية بل هي مطلقة في أحكامها لأنها تستتد إلى القرآن الكريم وتعاليمه التي لا تترك مجالا لتقسير مشتبه أو غامض من قبل الممارسين، أين يغدو كل واحد له قيمه وأخلاقه التي يفسرها حسب رلب رغبته وهواه. - أن العامل الغيبي (الآخرة) هو حقيقة مطلقة غير قابلـة للتبديل، والتسليم بها لله أثره على مستوى الممارسـة فمثلا: إن جودة عملية الإنتاج هي شيء بـالغ الأهميـة في أخلاقيـات التسـويق الإسـامي، فـالقرآن يقـرر أن سـامة المنتجـات

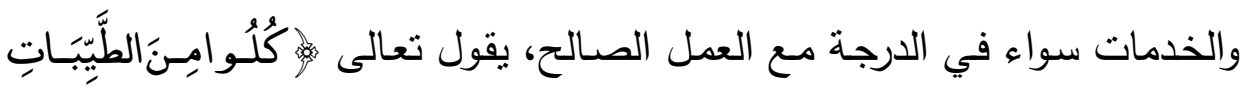

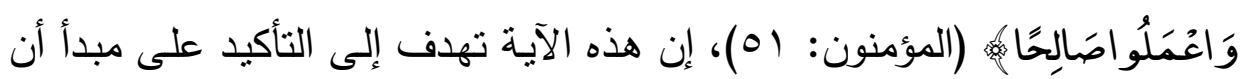
العمل الصـالح لا معنى لـه من دون نقاء وصـلاح في المسـائل المتعلقة بالإنتاج والاسـتهلاك والتسـويق للمنتجـات والخـدمات الطيـة المشـروعة، فعمليتـا الإنتـاج والاستهلاك لهما تصور مختلف تمامـا بالمقارنـة مـع الفكر الوضعي، إن المنظور 
الإســامي يـدمج العوامـل الغييـة والمعنويـة في عمليـة اتخـاذ القـرار التسـويقي، "فالعمل الصالح في ميدان التسويق يعني إيجاد المنتجات وتحسين مختلف الطرق التي تؤدي إلى انتقالها من المنتج أو البائع إلى الزبون أو المشتري النهائي أو الصناعي، بما يسمح لله من الحصول على ما يريد وبالتالي يقوم بتلبية حاجاته من هذه السلع والخدمات، وفي هذا يتتافس المسوقون في السوق في إطار من الأخلاق والسلوك القويم، فالإسـلام رغب في المنافسة ودعا إلى مباشرتها برفق مع إحاطتها بسياج من الأخلاق التي تمنع المسوق المسلم المنافس من الكيد للمنافسين الآخرين، وتعمد إيذائهم بمحاولة إخراجهم من السوق بشتى الطرق ليستأثز وحده بمغانمها"

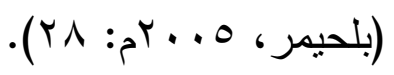

- إن المقاربـة الإسـلامية تؤكد على تعظيم القيمة في ضوء المصلحة العليا للمجتمع بدلا من السعي الأناني وراء تعظيم الأرباح، إن مبدأ تعظيم القيمة برتكز على مفهوم العدالة، هذا المفهوم الذي قام العديد من الباحثين في المجال بتحليل تطبيقاته عن طريق تصنيفها في "العمل النزيه" و "التعامل المنصف"، فالعمل النزيـه هـو الأخذ والعطـاء في مجـال الأعمـال التجاريـة وفقًا لمصـلحة جميـع الأطـراف المعنية، في حين أن التعامل المنصف هو الفضيلة التي تؤدي بالفرد إلى أن يكون

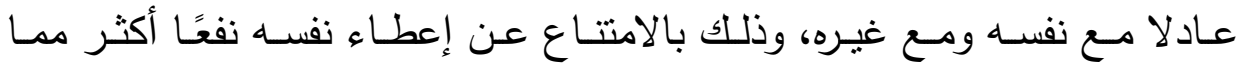
تستحق، أو إعطاء غيره أقل مما يستحقون، وكذلك بالامتتاع عن تفضيل نفسـه بأقل أذى في حين يصاب الآخرون بالأذى الأكبر، هذه هي قاعدة " لا ضرر ولا ضرار"، فإذا أصبحت العدالة جزءًا لا يتجزأ من تفاعلات التسويق فإن جوًا من بن فين الوئام والتعاون والاعتماد المتبادل سوف ينشأ، دون أن يكون لذلك أثر سلبي على الميزة التتافسية للمؤسسة (Saeed, et al. 2001, p.130)، حيث إن المنتج المسلم يسعى لتحقيق الربح في الحدود التي وضعتها الروح الإسـلامية، هذه الحدود تدمج المثل العليا للإسلام أين يصبح المنتج مدفوعا بامتثال تام لفكرة العدالة والرغبة في 
خدمـة المجتمـع وفي هذه الحالة فإن المؤسسـة تسـى لتحقيق أربـاح مرضية بـل

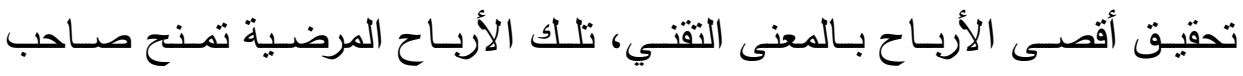

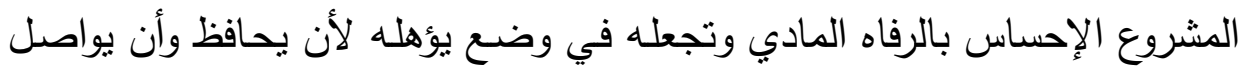

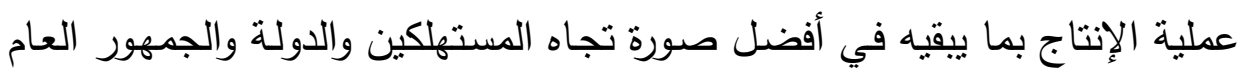
.(Salamah and Ruzita, 2007, p.07)

ثالثـا: الأســاس التثـريعي: "حرصـا على أن يكون الأداء التسـويقي سـليما يحقّق مصلحة الفرد والمجتمع، جعل الإسلام له ضوابط تحكمه وتوجّهه" (مروادي،

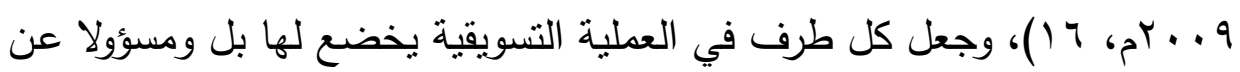
صيانتها والامتثال لها، ففي إطار الثربعة الإسـامية يمكن أن نصنف مسؤوليات رجل التسويق إلى أربع فئات (Saeed, et al., 2001, p.135):

(1) المسؤولية أمسام الله تبارك وتعالى الذي خلق البشر ووفر لهم الاستفادة من موارد الكون وذللها لهم لكسب رزقهم، (Y) مسؤولية المسوق تجاه نفسـه من

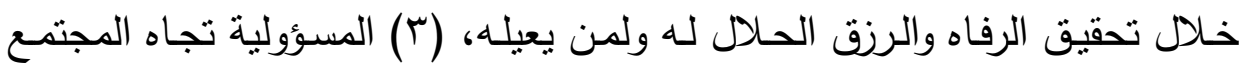
والتي تعني الحفاظ على حقوق المستهلكين من خلال سلامة المنتجات وطهارتها

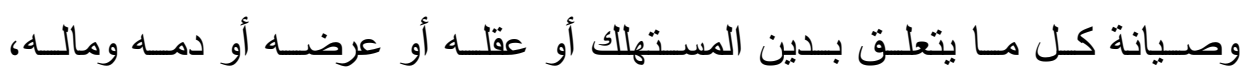
(ع) المسؤولية تجاه الكون والبيئة التي هي المحضن المؤقت الذي منحه الله للبشر من أجل تسهيل وجودهم على هذه الأرض.

غير أن التصور الإسلامي لا يلقي بالمسؤولية على المسوق فقط، فهو لا يلقيها على طرف دون الآخر بـل يجعلها شـركة بين جميع الأطـراف الفاعلـة في النظـام التسـوبقي (السـلطة المنظمـة للسـوق، والمؤسسـة، والمستهـلك والمجتمـع بصفة عامـة) والتي تخضع لنظام أخلاقي وتتربعي واحد يحدد لتلك الأطراف جميعها الصواب من الخطأ في مجال المعاملة الاقتصادية، حيث يقوم المنهج الإسلامي على تقوبم السلوك البشري وتهذيبه وتوجيهه بما يحقق المصلحة الفردية والجماعية. 
لقد عنيت الثريعة الإسلامية بالعلاقة بين البائع والمشتري (المنتج والمستهلك) وبالمعاملات الاقتصادية بشكل عام، فأوضحت دائرة الحلال وقاعدة الحرام التي يقوم عليها النشاط الاقتصـادي للإنسـان، منتجًا ومستهلكًا و ... إلخ، " فالثريعة الإسـلامية المستمدة من القرآن والسنة تغطي العلاقات الاقتصادية بين البائعين والمشترين، بين العاملين وأرباب العمل، بين المقرضين والمقترضين.. علما أنه لا فرق في التعامل مع مسلم أو غير مسلم في عين الثريعة الإسـلامية.. يجب أن يعامل كلاهما بعدل ونزاهة وإنصاف" (Rice, 1999, p.349).

والمتتبع للآيات القرآنية والأحاديث النبويةوآثار السلف يدرك مدى تلك العناية البارزة، التي ربطت السلوك التجاري للمسلم بشريعته الربانية، في حين انسلخت المفاهيم الوضعية عن الجوانب الروحية والأخلاقية، وركزت على الجوانب المادية في النشاطات الاقتصادية، حتى أصبح كثير منهم يرى مثلا أن عبارة "أخلاقيات التسـويق" تضـم لفظتين متتاقضـتين (oxymoron) لا يمكن الجمـع بينهــا، وأن

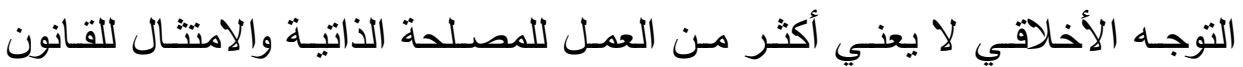
الوضـعي (Gaski, 1999)، ولعل هذا يبرز مدى مـا يملكه المجتمـع المسلم من تعاليم اقتصـادية إسـامية، منميزًا عن غيره من المجتمعات التي عرفت مذاهب وضعية، هذا التميز هو الذي جعل (Bagozzi) الذي تحدث عن مركزية المصلحة الذاتية في مفهوم التبادل التسويقي، يستدرك على تلك المركزبة وبستثي قائلا:" إن الاعتماد الحصري على أن الإنسان مخلوق يسعى إلى تحصيل اللذة وتجنب الألم قد يجعل نظرتتا لطبيعية الإنسان قاصرة، نعم، ففي بعض المجتمعات تغلب - إن لم نقل تهيمن - قيم المجموعة والأسرة على القيم الاجتماعية والاقتصادية، بل أكثر من ذلك، فإن العديد من المجتمعات غير الغربيـة لديها تركيز أقل على المنفعـة المادية، حيث إنهم يركزون ويؤكدون على الكيانات والقيم غير المادية مثل: احترام الطبيعة، والبساطة، وتحقيق الذات، والتواصل، والأخوة، والسلام، والحب للإنسانية، 
ليس فقط من أجل تذليل صعوبات تسعير وتبادل المنتجات ولكن طريقة استهلاك

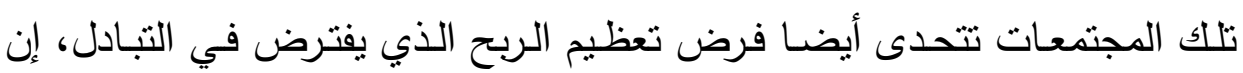

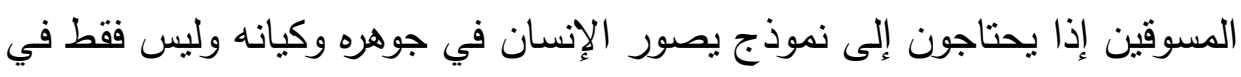
استهلاكه السلع والخدمات" (Bagozzi, 1975B, p.319).

\section{الخلاصة}

مـن هذه المناقتــة نخلص إلى أن مبادئ التسـويق في الإسـام تجمـع بين

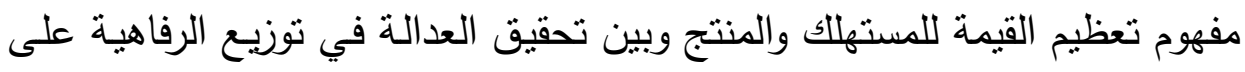

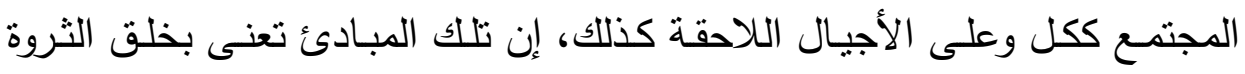

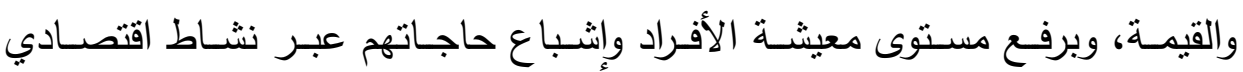
منضبط بأخلاق الإسلام وتوجيهاته التي تضمن في الوقت ذاته درية حرية المستهلكين

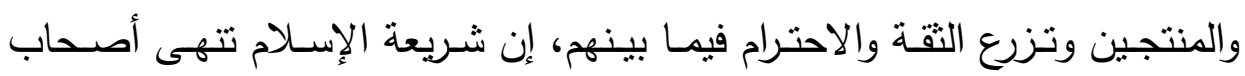

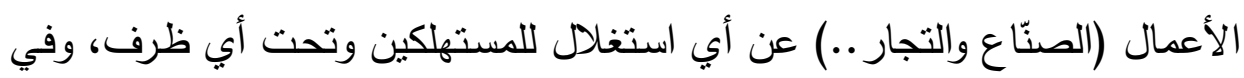

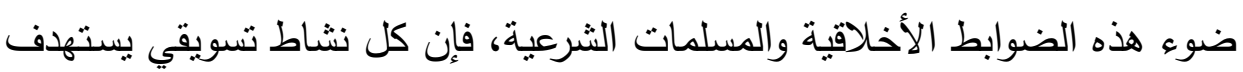

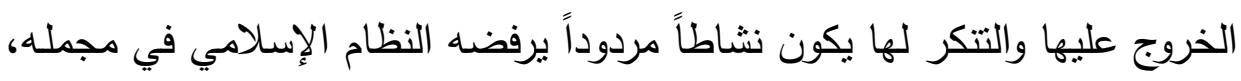

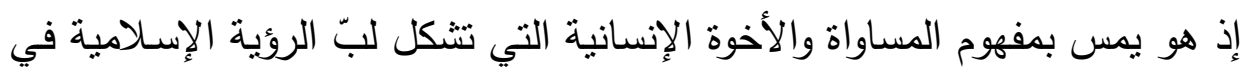
هذا الباب (Abul Hassan, et al., 2008)، كما أنه يمس العقيدة الإسلامية وينال

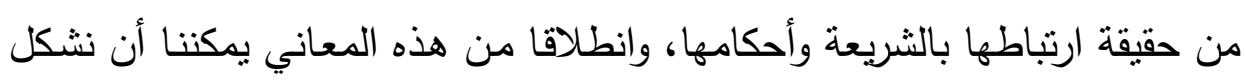

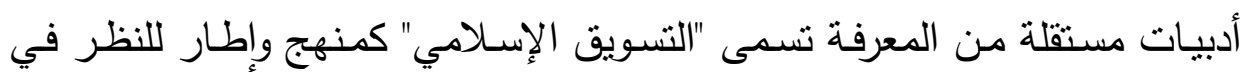

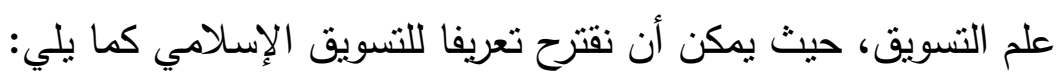

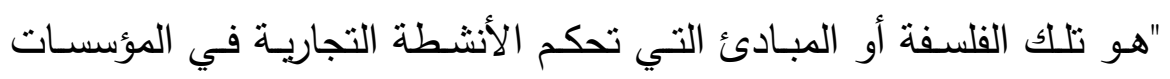

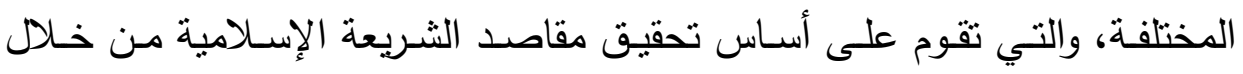

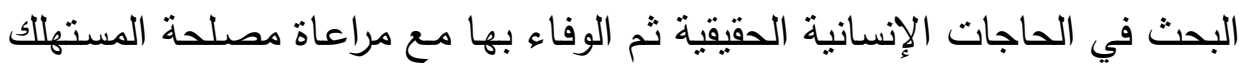

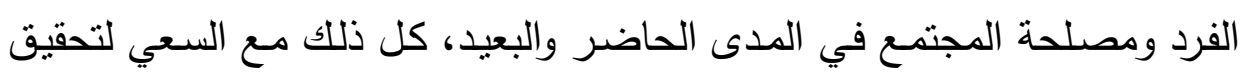


الأهداف التجاربة للمؤسسات بالوسائل المباحة وبما يتوافق مع روح الإسـلام عقيدة وأخلاقا وشريعة".

وبالنهايـة، وعلى الرغم من أن هذا البحث هو جهد المقل، فقد حاولنا من خلاله تقديم إطار لمفهوم التسويق في الإسلام، هذا الإطار ما زال يحتاج إلى مزيد مـن النقاش والإثراء بغيـة الخروج بنمـذج متكامـل لنظريـة تسـويق إسـلامي. والله

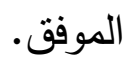

\section{المراجع}

أولاً: المراجع العربية

بلحيمر، إبراهيم (0 rم) المزيج التسويقي من منظور التطبيقات التجارية الإسلامي، رسالة دكتوراه غير منشورة، جامعة الجزائر .

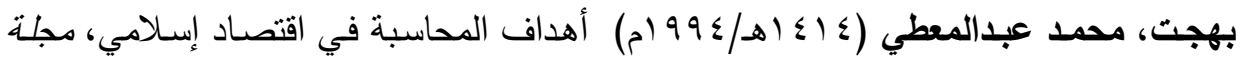

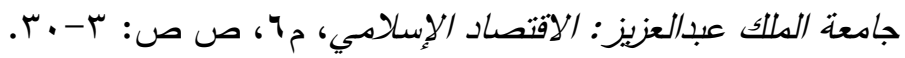

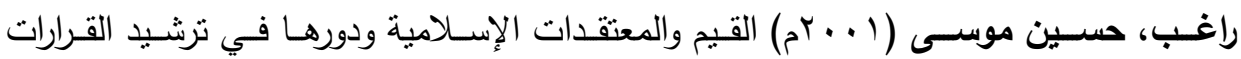

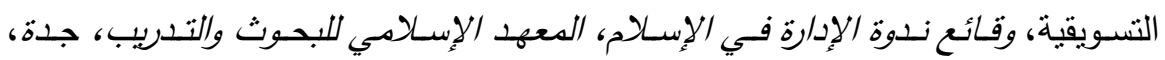
الطبعة الثانية.

الثنواني، صلاح ( . . . rم) الإدارة التسويقبة الحديثة ، مؤسسة شباب الجامعة، الإسكندرية.

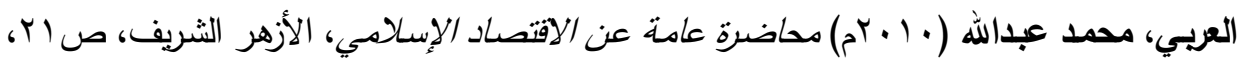
نقلا عن محمود الوادي وآخرون، الاقتصاد الإسلامي، دار المسيرة للنشر ، الأردن.

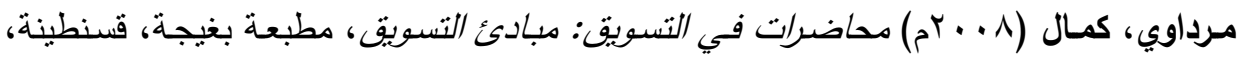
الجزائر مـرداوي، كمـال (9 . . rم) الأزمـة الماليـة العالميـة خلفياتها التسـويقية، تـداعياتها الاقتصـادية،

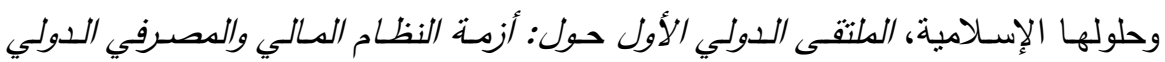

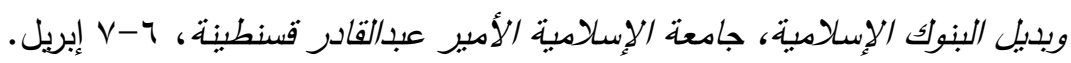




\section{ثانيًا: المراجع الإنجليزية}

Abul Hassan, et al., (2008) Islamic Marketing Ethics and Its Impact on Customer Satisfaction in the Islamic Banking Industry, Journal of King Abdulaziz University: Islamic Economics, 21(1): 27-46

Anusorn S., Janet, M., Kumar, R. and Rao, C.P. (2000) Toward an Understanding of Religiousness and Marketing Ethics: An Empirical Study, Journal of Business Ethics, 27(4): 305-319.

Arham, Muhammad (2010) Islamic perspectives on marketing, Journal of Islamic Marketing, 1(2): 149-164.

Arnould, M. and Fisher, J. (1996) Counterculture, Criticisms, and Crisis: Assessing the Effect of the Sixties on Marketing Thought, Journal of Macromarketing, 16(1): 118-133.

Bagozzi, Richard (1975A) Marketing as exchange, Journal of Marketing, 39(October): 32-39.

Bagozzi, Richard (1975B) Social Exchange in Marketing, Journal of the Academy of Marketing Science, 3(Fall 1975): 314-327.

Bell, Martin and Emory, William (1971) The faltering marketing concept, Journal of Marketing, 35(October): 37-42.

Boltanski, L. and Shiapello, E. (2005) The New Spirit of Capitalism, London, Uk.

Brei and Böhm (2008) Lacking Capitalism: Desiring Marketing in Times of Capitalist crisis, Working Paper No. WP 08/12, Essex Business School, pp: 1-16.

Choudhury, Masudul, Alam (2000) Regulation in the Islamic Political Economy: Comparative Perspective, Journal of King Abdulaziz University: Islamic Economics, 12: 21-51.

Crane and Desmond (2002) Societal Marketing and Morality, European journal of marketing, 36(5/6): 548-569.

Demeure, Claude (2008) Marketing, 6eme édition, Dunod, Paris.

Doyle, Jim (2010) An Investigation of Pricing Data for Evidence of Institutional-Level Relationship Marketing Behaviors, Journal of Relationship Marketing, 9(4): 264278.

Drucker, Peter (1986) Management-Tasks, Responsibilities, Practices, First Edition, Truman Talley Books, Dutton.

Ford, Henry and Grow, her Samuel (1923) My Life and Work, Project Gutenberg eBook., online 2005.

Gaski, J.F. (1999) "Does Marketing ethics really have anything to say? - A Critical Inventory of the Literature", Journal of Business Ethics, 18: 315-334.

Geoff and Paul (2005) Management-of-Marketing, Elsevier Butterworth-Heinemann, Oxford.

Gibbs, Paul and Ilkan, Mustafa (2008) The ethics of marketing in Muslim and Christian communities, Cross Cultural Management, 15(2): 162-175.

Gregory, Elliott (1990) The Marketing Concept - Necessary, but Sufficient An Environmental View, European Journal of Marketing, 24(Iss 8): 23-30.

Jobber, David and Lancaster, Geoff (2009) Selling And Sales Management, $8^{\text {th }}$ edition, Pearson Education, UK. 
Kale, S.H. (2004) "Spirituality, religion and globalization", Journal of Macromarketing, 24(2): 92-107.

Keith, Robert (1960) The Marketing Revolution, Journal of Marketing, pp: 35-39.

Kotler (2003) Marketing insights from A to Z, John Wiley \& Sons, Inc., Hoboken, New Jersey.

Kotler and Armestrong (2008) Principles of Marketing, 12th Edition, Pearson Education International, New Jersey.

Kotler, et al., (1999) Principles of Marketing_2nd_europian_edition, Prentice Hall Europe.

Kotler, Kartajaya and Setiawan (2010) Marketing 3: From Products to Customers to the Human Spirit, Hoboken, New Jersey.

Kotler, Philip (2002) Marketing Management Millenium Edition, Tenth Edition, Pearson Custom Publishing, Boston.

Kotler, Philip (2004) Wrestling with Ethics; Is marketing ethics an oxymoron?, Journal of Marketing management, 13(6): 30-37.

Lancaster and Massingham (2011) Essentials of Marketing Management, Routledge, New York.

Lazer, William (1969) Marketing's Changing Social Relationships, The Journal of Marketing, 33(1), (Jan.): 3-9.

Levitt, Theodore (1975) Marketing Myopia, Harvard Business Review.

Mahabub, Alom and Shariful, Haque (2011) Marketing An Islamic Perspective, World Journal of Social Sciences, 1(3), July 2011: 71-81.

Martine, Bechtold et Jean-René Loubat (2010) L'éthique en temps de crise, Revue Française du Marketing - Mars- № 226 - 1/5.

Payne, Adrian (1988) Developing a Marketing-Oriented Organization, Business Horizons, (May/June): 46-53.

Philips, Charls (1941) A Critical Analysis of Recent Literature Dealing with Marketing Efficiency, The Journal of Marketing, 5(4), Apr,: 360-365.

Powers, Thomas (1991) Personal selling in the early twentieth century: From America's. Darling to it's scapegoat, Proceedings of the Fifth Conference on Historical Research in Marketing and Marketing Thought, Kellogg Center of Michigan State University.

Pride, William M. and Ferrell, O.C. (2000) Marketing, Concepts and Strategies, Boston, Houghton Mifflin Company.

Rice, G. (1999) Islamic ethics and the implications for business, Journal of Business Ethics, 18: 345-58.

Russell, Edward (2010) The Fundamentals of Marketing, AVA Publishing SA, Lausanne.

Saeed, Md., Ahmed, Z.U. and Mukhtar (2001) International Marketing Ethics from an Islamic Perspective: A Value-Maximization Approach, Journal of Business Ethics, 32: 127-142.

Saji and Mukundadas (2007) Corporate Societal Marketing and the Process of Building Corporate Brand Equity: The Case of Malayala Manorama, International Marketing Conference on Marketing \& Society, 8-10 April, IIMK,: 507-511. 
Salamah and Ruzita (2007) A Survey on the Objective of the Firm and Models of Producer Behavior in the Islamic Framework, Journal of King Abdulaziz University: Islamic Economics, 20(2): 3-16.

Shankar Avi et al (2006) Heaven knows I'm miserable now, Marketing Theory, 6(4): 485-505.

Shapiro, Benson (1973) Marketing for Nonprofit Organization, Harvard Business Review, (September-October): 123-132.

Shaw, Arch (1915) Some Problems in Market Distribution, Harvard University Press.

Svensson, Goran (2005) The spherical marketing concept, European Journal of Marketing, 39(1/2): 5-15.

Vandercammen, Marc (2002) Marketing: l'essentiel pour comprendre, décider, agir, De Boeck Supérieur, Bruxelles.

Varey, Richard (2011) A Sustainable Society Logic for Marketing, Social Business, 1(1): 69-83.

Venkatesh, A. and Peñaloza, L. (2006) From Marketing to the Market: A Call for Paradigm Shift, in Does marketing need reform? : fresh perspectives on the future, edited by Jagdish N. Sheth \& Rajendra S. Sisodia, M.E. Sharpe, Inc, New York.

Wilkie, William L. and Moore, Elizabeth S. (2007) What Does the Definition of Marketing Tell UsAbout Ourselves?, Journal of Public Policy \& Marketing, 26(2) Fall 2007: 269-276. 


\title{
The Modern Concept of Marketing, An Islamic Perspective
}

\author{
Tarek Belhadj \\ Assistant Professor \\ Institute of Commercial Sciences and Management \\ University Centre Mila- Algeria
}

\begin{abstract}
In this article, we have discussed the main stages undergone by the marketing thought until it arrived to its modern concept. And by sitting those stages in consideration and analysis, we provided some critical comments. We have tried through which to highlight an important feature in the modern marketing system, which is the change of concepts and principles based on, depending on the economic and social transformations witnessed by the Western societies and crises experienced by the capitalist system. This what makes it - from our point of view - lacks the consistency and stability. From that, we have tried to provide an Islamic perspective on marketing, based on the fixed principles of justice and equity, and on general assets find its firm roots in the spiritual, ethical and legislative values of our religion, where we have suggested a definition of the concept of Islamic Marketing.
\end{abstract}

